\title{
A three-regime model of speculative behaviour: modelling the evolution of the S\&P 500 composite index
}

Article

Accepted Version

Brooks, C. and Katsaris, A. (2005) A three-regime model of speculative behaviour: modelling the evolution of the S\&P 500 composite index. The Economic Journal, 115 (505). pp. 767797. ISSN 1468-0297 doi: https://doi.org/10.1111/j.14680297.2005.01019.x Available at https://centaur.reading.ac.uk/20554/

It is advisable to refer to the publisher's version if you intend to cite from the work. See Guidance on citing.

Published version at: http://dx.doi.org/10.1111/j.1468-0297.2005.01019.x

To link to this article DOI: http://dx.doi.org/10.1111/j.1468-0297.2005.01019.x

Publisher: Wiley

All outputs in CentAUR are protected by Intellectual Property Rights law, including copyright law. Copyright and IPR is retained by the creators or other copyright holders. Terms and conditions for use of this material are defined in the End User Agreement.

www.reading.ac.uk/centaur 
Central Archive at the University of Reading

Reading's research outputs online 
This is the authors' accepted manuscript of an article published in the Economic Journal. The definitive version is available at www3.interscience.wiley.com 


\title{
A Three-Regime Model of Speculative Behaviour: Modelling the Evolution of the S\&P 500 Composite Index*
}

May 2004

Chris Brooks and Apostolos Katsaris

\begin{abstract}
In this paper we examine whether a three-regime model that allows for dormant, explosive and collapsing speculative behaviour can explain the dynamics of the S\&P 500 Composite Index for the period 1888-2003. We extend existing two-regime models of speculative behaviour by including a third regime that allows for a bubble to grow at a steady growth rate, and examine whether other variables, beyond the deviation of actual prices from fundamental values, can help predict the level and the generating state of returns. We propose abnormal volume as an indicator of the probable time of the bubble collapse and thus include abnormal volume in the state and the classifying equations of the surviving regime in the explosive state. We show that abnormal volume is a significant predictor and classifier of returns. Furthermore, we find that the spread of the 6-month average of actual returns above the 6-month average of fundamental returns can help predict when a bubble will enter the explosive state. Finally, we examine the financial usefulness of the three-regime model by studying the Sharpe ratios of profits of a trading rule formed using inferences from it. Use of the three-regime model trading rule leads to higher Sharpe ratios and end of period wealth than those obtained from employing existing models or a buy and hold strategy.
\end{abstract}

Keywords: speculative behaviour models, fundamental values, dividends, regime switching, speculative bubble tests, trading rules.

JEL Classifications: C51, C53, G12

\footnotetext{
*The authors are both of the ISMA Centre, University of Reading. Contact: Chris Brooks, ISMA Centre, University of Reading, PO Box 242, Whiteknights, Reading, RG6 6BA, UK. Tel: +44 (0) 11893167 68; Fax: +44 (0) 1189314741 ; Email: C.Brooks@rdg.ac.uk We are grateful to three anonymous referees for extensive comments on a previous version of this paper. We are also grateful to Phillip Xu, Ryan Davies, David Oakes, Menelaos Karanasos, Karim Abadir, Apostolos Filippopoulos, Sarantis Kalyvitis and seminar participants at the Department of Economics and Related Studies at the University of York, and at the Department of International and European Economic Studies at the Athens University of Economics and Business for useful comments and suggestions. We are responsible for any remaining errors.
} 


\section{Introduction}

The evolution of prices in equity markets during the 1920's, the 1980's and the late 1990's, has puzzled economists and market participants. During these periods, market prices displayed significant growth followed by abrupt market collapses. It is hard to reconcile this behaviour with the variation of fundamentals during these periods and thus two alternative theories have been developed that try to explain why stock markets appeared to be moving without fundamental justification. The first approach attributed these abrupt changes in the market trend to a non-linear relationship between actual prices and fundamental values. The second approach supports the view that self-fulfilling expectations and speculative bubbles caused the significant and increasing divergence of actual prices from fundamental values.

Initially, studies on the relationship between actual prices and fundamental values focused on the indirect identification of speculative bubbles in financial data (see Shiller (1981), Blanchard and Watson (1982), West (1987), Diba and Grossman (1988)). However, indirect tests of bubble presence suffered from potential problems of interpretation since bubble effects in stock prices could not be distinguished from the effects of unobservable market fundamentals. For this reason, direct bubble tests, which test directly for the presence of a particular bubble specification on stock market returns, were developed (see Flood and Garber (1980), Flood, Garber and Scott (1984), Summers (1986), Cutler, Potterba and Summers (1991), McQueen and Thorley (1994), Salge (1997), van Norden and Schaller (1999)). Under these tests, researchers select the type of bubble that they suspect might be present in the data and then examine whether this form of speculative bubble has any explanatory power for stock market returns.

Although several different types of bubbles have been examined in the literature, periodically collapsing speculative bubbles, first proposed by Blanchard and Watson (1982), have attracted increasing attention, especially in the late 1990's. Models of periodically collapsing speculative bubbles are able to capture several stylised characteristics of historical accounts of "manias and panics" (Kindleberger (1989)). The common characteristic of many such periods is that prices initially diverge from fundamental values in a systematic and increasing fashion. As time passes, the rate of divergence accelerates and thus prices increase without bound and this exponential trend is followed by a sharp reversal of market prices to fundamental values when market participants realise that the current price level is unsustainable.

In order to empirically examine the presence of periodically collapsing bubbles, researchers in recent years have focused on the construction of direct bubble tests that can identify such stochastic bubble processes in financial and macroeconomic data. More specifically, Evans (1991) and van Norden and Schaller (1993) show how periodically collapsing speculative bubbles can induce regime switching behaviour in asset returns. Regime switching in asset returns and speculative behaviour have been linked 
in several studies. Van Norden and Schaller (1993) and van Norden (1996) show that a two-regime speculative behaviour model has significant explanatory power for stock market and foreign exchange returns during several periods of observed market over- and under-valuations. Hall, Psaradakis and Sola (1998) test for the presence of collapsing speculative bubbles in Argentinean monetary data using a univariate Markov-switching ADF test and find evidence of a speculative bubble in consumer prices in the period June 1986 to August 1988.

van Norden and Vigfusson (1998) compare the van Norden and Schaller (1997) approach with the Hall, Psaradakis and Sola (1998) switching stationarity test for the presence of speculative bubbles and find that both models have significant power in detecting periodically collapsing speculative bubbles. However, both approaches concentrate on the explosive phase of the speculative bubble since it is during this phase that asset prices display significant patterns of bubble behaviour. For this reason, both models are constructed to identify periods of explosive stock market growth followed by a sharp reversal. This specification of the bubble tests implicitly assumes that a speculative bubble will always display explosive growth, although this will be limited for small bubble sizes. This is an unrealistic assumption since there are periods during which asset prices display constant growth or mimic the behaviour of fundamentals. During such periods the speculative bubble can be assumed to be 'dormant' since it grows at a steady rate. A speculative bubble process that can replicate this switch from a dormant to an explosive state is described in Evans (1991). However, Evans uses this bubble process only in a simulation study and does not provide empirical evidence concerning the presence of such speculative bubbles in asset prices.

In what follows, we try to fill this gap by showing how the van Norden and Schaller (1999) model can be extended to allow for asset price behaviour of the form described in Evans. We do this by incorporating a third regime in which the bubble grows at the fundamental rate of return. We then examine whether the three-regime speculative behaviour model has explanatory power for U.S. stock market returns. Additionally, we show that other variables, such as abnormally high volume, can be used in the van Norden and Schaller framework in order to model the probability of a bubble collapse more effectively ${ }^{1}$.

Furthermore, extant research has focused only on the issue of identifying the presence of speculative bubbles. Although the identification of a speculative bubble is useful in determining whether market participants are rational and whether markets are efficient, it is also interesting to examine the financial usefulness of speculative bubble models by testing whether such models can be used to generate abnormal trading profits or return profiles that typical investors would consider more desirable than those of a buyand-hold strategy. We do this by formulating a trading rule that exploits information about the implied probability of a stock market crash or rally derived from switching regime speculative behaviour models.

\footnotetext{
${ }^{1}$ Brooks and Katsaris (2002) have examined the usefulness of volume as a classifier and predictor of excess returns in the context of the van Norden and Schaller (1999) 2-regime model.
} 
This allows us to evaluate the predictive ability of our three-regime model against the van Norden and Schaller model in a financially intuitive manner: by determining which model can lead to higher Sharpe ratios. Very little existing research has been able to pinpoint major market downturns, although one exception is Maheu and McCurdy (2000), who use a Markov switching model to identify bull and bear runs in stock markets, although they do not examine the model's financial usefulness. We also examine the market timing ability of speculative behaviour models by comparing the results of the trading rule to those of a buy and hold strategy and those of randomly generated trading rules. Finally, we employ a longer sample than in the original van Norden and Schaller study, examining the returns on the S\&P 500 for the period January 1888 to January 2003.

The rest of this paper is organised as follows. In section 2, we derive the three-regime speculative behaviour model. Section 3 presents the data and the methodology used to construct fundamental values. Section 4 presents the results of the speculative behaviour models while in section 5 we examine the out of sample forecasting ability and profitability of the speculative behaviour trading rules. Section 6 concludes.

\section{A Three-Regime Speculative Behaviour Model}

An extensive theoretical literature exists concerning the development of rational speculative bubbles (see, for example, Blanchard (1979), Blanchard and Watson (1982), West (1988), Diba and Grossman (1988), and Kindelberger (1989)). In the Blanchard and Watson (1982) model, the speculative bubble would burst to zero in the collapsing state, and therefore it could not regenerate. The possibility of negative bubbles was also explicitly ruled out. An important recent innovation was the model proposed by van Norden and Schaller (1999), where the size and probability of bubble collapse are dependent on bubble size and where both positive and negative bubbles are permitted, and where partial bubble collapses are permissible (the latter are also considered by Evans (1991) and Hall and Sola (1993)). van Norden and Schaller estimate the model using data on the value-weighted index of all stocks from the Centre for Research on Security Prices (CRSP) database for the period January 1926 to December 1989. Their results show that there is non-linear predictability in stock market returns and that the deviations of actual prices from fundamental values are a significant factor in predicting both the level and the generating state of returns. They find that the model has explanatory power for several periods of apparently speculative behaviour of the data, since the probability of a crash increases significantly prior to large stock market declines while the probability of a rally is high prior to large stock market advances.

Although the van Norden and Schaller approach can be used directly to test for the presence of periodically partially collapsing speculative bubbles, it has several limitations. Firstly, van Norden and Schaller do not provide any information on the out of sample forecasting ability of their model. Furthermore, their model provides limited information as to the likely time of a bubble collapse, since the probability of a collapse is solely dependent on the bubble size. This leads to long periods of high 
probabilities of collapse, when the bubble deviation is persistently high. Moreover, although the power of the speculative behaviour model to detect bubbles of the form described by Evans (1991) has been examined by van Norden and Vigfusson (1998), the financial usefulness of this model has not, to our knowledge, been examined. It would thus be interesting to determine whether this model can be used in order to time large market falls. Finally, the van Norden and Schaller model examines only the explosive state of a speculative bubble since it is during this state that asset prices display apparent bubble behaviour. This implies that their model assumes that the bubble will always induce explosive behaviour in asset prices; the asset price will either grow with explosive expectations or will reverse to fundamental values. However, it is possible (and casual observation of bubbly series provides support for the idea) that speculative bubbles in stock markets may alternate between 'dormant' and explosive states ${ }^{2}$. During the dormant state, the bubble grows at the required rate of return without explosive expectations since the probability of a crash is zero or negligible, as in the Evans (1991) model. In such periods, the actual returns on the asset are equal to the returns on the fundamentals, plus a random disturbance and thus actual prices mimic the behaviour of fundamental values. This bubble behaviour is more consistent with a threeregime speculative model. This switching between a dormant bubble state and an explosive bubble state can be observed in the early 1920's, the early 1950's, the 1960's and the early 1990's amongst other periods, when bubbles alternate between growing at a small steady growth rate and an increasingly explosive growth rate. However, as seen from the results of van Norden and Schaller, their model will always assign a small but positive probability of the bubble collapsing, and this probability will affect the expected returns on the asset. This will cause a positive bias in the estimates of the probability of collapse at every point in time and especially during periods when the bubble displays constant growth. It is therefore preferable to construct a speculative behaviour model that explicitly allows for dormant periods as well as for explosive bubble growth.

We will now show how the van Norden and Schaller model can be extended to a three-regime speculative behaviour model. The latter describes a process in which the expected size of the bubble in the next time period can be generated from one of three regimes: a deterministic (or 'dormant') regime $(D)$, a survivingexplosive regime $(S)$, and a collapsing-explosive regime $(C)$. It is worth stating at the outset that our model, whilst it is a regime-switching model, it is not a Hamilton-style Markov-switching model, since the probability of being in a particular regime at time $t+1$ does not depend directly on the state at time $t$. The bubble of the next time period can be generated from any of the three regimes. In order to classify the behaviour into one of the three regimes, several variables may be significant, although the relative size of the bubble is expected to play a predominant role. The model will now be defined.

\footnotetext{
${ }^{2}$ Bohl (2000) suggests the use of a threshold autoregressive model in a cointegration framework to separate periods of deterministic from explosive bubble growth.
} 
Following Evans (1991), in regime $D$, the bubble size is small and thus investors believe that the bubble will continue to grow at a constant mean rate $(1+i)$ :

$$
E_{t}\left(b_{t+1} \mid W_{t+1}=D\right)=(1+i) b_{t}
$$

where $b_{t}$ is the size of the bubble (the difference between the actual and fundamental price) at time $t, i$ is a constant discount rate, and $W_{t}$ is an unobserved indicator that determines the state in which the process is at time $t$. This regime implies that investors believe that the bubble has a negligible probability of collapse and thus they do not expect to be rewarded for this probability with an excess return. Evans (1991) assumes that once a bubble crosses a certain threshold, it erupts into an explosive regime in which the bubble continues to grow or collapses to a smaller value. Evans (1991) arbitrarily assumes a threshold value, whereas we model the probability of being in regime $D$. The probability of being in regime $D$ in time $t+1$ is denoted $n_{t}$, and is dependent on the bubble's relative size and on other variables observed at time $t^{3}$; this probability will be defined precisely later.

Even when the bubble is in the dormant regime, investors know that there is a probability that the bubble might enter an explosive state in which the bubble continues to grow with explosive expectations or collapses to a smaller value. The probability of being in this explosive state is $1-n_{t}$. In this explosive state, there are two underlying regimes: the surviving regime that occurs with probability $q_{t}$ and the collapsing regime that occurs with probability $1-q_{t}$. In the collapsing regime $(C)$, the size of the bubble is given by:

$$
E_{t}\left(b_{t+1} \mid W_{t+1}=C\right)=g\left(B_{t}\right) p_{t}^{a}
$$

where $g\left(B_{t}\right)$ is a continuous and everywhere differentiable function such that, $g(0)=0$ and $0 \leq \partial g\left(B_{t}\right) / \partial B_{t} \leq 1^{4}, B_{t}$ is the relative size of the bubble in period $t\left(B_{t}=b_{t} / p_{t}^{a}\right)$, and $p_{t}^{a}$ is the actual asset price at time $t$. This function is only for theoretical use and will not be imposed on the data. From (1) and (2) and since:

$$
E_{t}\left(b_{t+1}\right)=n_{t}\left(E_{t}\left(b_{t+1} \mid W_{t+1}=D\right)\right)+\left(1-n_{t}\right)\left[q_{t}\left(E_{t}\left(b_{t+1} \mid W_{t+1}=S\right)\right)+\left(1-q_{t}\right)\left(E_{t}\left(b_{t+1} \mid W_{t+1}=C\right)\right)\right]
$$

we can show that the expected size of the bubble in the surviving regime will be:

$$
E_{t}\left(b_{t+1} \mid W_{t+1}=S\right)=\frac{(1+i)}{q_{t}} b_{t}-\frac{\left(1-q_{t}\right)}{q_{t}} g\left(B_{t}\right) p_{t}^{a}
$$

\footnotetext{
${ }^{3}$ Note that the $n_{t}$ is used to denote the probability of being in regime $D$ rather than $d_{t}$, since the latter conflicts with the standard notation that we adopt later for dividend payments.

${ }^{4}$ In the original van Norden and Schaller model (1993), the bubble size in the collapsing regime is $u\left(B_{t}\right) p_{t}^{a}$ where $0 \leq \partial u\left(B_{t}\right) / \partial B_{t} \leq 1$. This implies that in the collapsing regime, the original van Norden and Schaller model states that the bubble in period $t+1$ is expected to be equal to or smaller than the bubble in period $t$. We use a slightly different notation and assume that the bubble size is $g\left(B_{t}\right) p_{t}^{a}$ where $0 \leq \partial g\left(B_{t}\right) / \partial B_{t} \leq(1+i)$. This implies that the bubble in the collapsing regime is smaller than the bubble in the 'dormant' state and therefore, when the bubble does not yield the required rate of return, it is considered to be in the collapsing state.
} 
At any point in time, the conditional probability of observing the surviving regime in the next time period is given by $\left(1-n_{t}\right) q_{t}$ and the probability of observing the collapsing regime is $\left(1-n_{t}\right)\left(1-q_{t}\right)$. Grouping together (1), (2) and (4), the bubble of the next time period will be generated by the following stochastic process:

$$
\begin{aligned}
& M b_{t} \quad \text { with probability } n_{t} \\
& b_{t+1}=\quad \frac{M}{q_{t}} b_{t}-\frac{\left(1-q_{t}\right)}{q_{t}} g\left(B_{t}\right) p_{t}^{a} \quad \text { with probability }\left(1-n_{t}\right) q_{t} \\
& g\left(B_{t}\right) p_{t}^{a} \quad \text { with probability }\left(1-n_{t}\right)\left(1-q_{t}\right)
\end{aligned}
$$

where $M=(1+i)$ is the gross fundamental return on the security.

At this point, it is useful to note three important differences between this model and the Evans (1991) data generating process. First, we allow for the existence of negative (price decreasing) bubbles, and second, in Evans, a strictly positive bubble must cross the arbitrary threshold in order to enter the explosive regime. Finally, he assumes that the probability of collapse in state $D$ is zero, whereas we do not actually impose this on the data.

In (5), we assume that when the bubble is in the dormant regime, the bubble follows a deterministic process. This is because the probability of observing a collapse when the bubble is in regime $D$ is so small that investors decide to ignore it Note that our model produces a very small probability of being in regime $C$ in the next time period $\left(\left(1-n_{t}\right)\left(1-q_{t}\right)\right)$ if the probability of being in regime $D$ in the next time period is very high.

We can show that the expected gross total return of the next period, $r_{t+1}$, if the bubble is generated by the dormant regime $(D)$, is $^{5}$ :

$$
E\left(r_{t+1} \mid W_{t+1}=D\right)=M
$$

Equation (6) states that the expected gross return on the asset, if the bubble is generated by the dormant regime in the next time period, is equal to the required rate of return on the bubble-free asset. Gross returns are calculated as $r_{t+1}=\left(P_{t+1}{ }^{a}+d_{t+1}\right) / P_{t}^{a}$ and they therefore include dividend payments. However, as the bubble grows, the probability of being in the steady growth regime diminishes and thus the probability of being in the explosive state (surviving or collapsing regime) increases. In this explosive state, as the bubble increases, the probability of being in the surviving state diminishes, causing the probability of collapse to increase geometrically. In the explosive state, investors perceive that the bubble can now collapse and thus take into account the probability of a crash. The expected return in the surviving regime is:

\footnotetext{
${ }^{5}$ Proofs of the equations are not presented here in the interest of brevity but are available in an appendix from the authors upon request.
} 
$E_{t}\left(r_{t+1} \mid W_{t+1}=S\right)=M+\frac{\left(1-q_{t}\right)}{q_{t}}\left(M B_{t}-g\left(B_{t}\right)\right)$

In equation (7), investors adjust their expectations for the next period return to take into account the probability of collapse. If the bubble collapses, the gross expected return is given by:

$$
E\left(r_{t+1} \mid W_{t+1}=C\right)=M+g\left(B_{t}\right)-M B_{t}
$$

In equation (8), the gross return in the collapsing regime is a function of the required return on the bubbly asset and the relative size of the bubble in the collapsing regime. The magnitude of the return depends on the function $g\left(B_{t}\right)$, a function that does not require specification since the model will subsequently be linearised.

It is straightforward to see that the above bubble model collapses to the original van Norden and Schaller model if we set the probability of being in the dormant regime equal to zero. Furthermore, if we fix the probability of survival to a constant value and set the bubble size in the collapsing regime equal to zero then the model collapses to the original Blanchard and Watson (1982) model. Finally, the probabilityweighted expected return on the asset at any point in time is $M$, and this is also the ex ante bubble growth rate. This comprises the expected return in state $D$, which is $M$, and a return higher than $M$ in state $S$ and lower than $M$ in state $C$.

Nothing has yet been said about the probabilities $n_{t}$ and $q_{t}$ apart from that they are negative functions of the size of the bubble. Let us examine these probabilities in more detail. From the original Evans (1991) model, as the bubble grows, the probability of being in the dormant regime $(D)$ decreases. Here we consider both positive and negative bubbles and therefore we formulate the probability $n_{t}$ as a function of the absolute size of the bubble. However, the size of the bubble may not be the only variable that investors examine in order to decide whether the bubble is in the dormant or the explosive state.

In order to model the probability of being in the dormant regime in the next time period, we base our intuition on the results of Harvey and Siddique (2000) and Chen, Hong and Stein (2001), who find that when returns have been high in the recent past, the skewness in future returns is more negative. This implies that high average returns will tend to be followed by large negative returns. From equation (6), the expected bubble returns in the dormant regime are indistinguishable from the expected fundamental returns. However, when the bubble enters the explosive state and survives, we know from (7) that it yields increasingly larger returns than the bubble-free asset. For this reason, it is plausible to assume that when investors observe larger average actual returns than average fundamental returns in the near past they will conclude that the bubble must have entered the explosive state. The probability of being in the dormant regime falls as the bubble grows, so that time spent in the surviving regime will reduce the probability of being in regime $D$, ceteris paribus, since it tends to increase the size of the bubble. This means that large 
positive returns imply a smaller probability of being in the 'dormant' regime in the near future. Chen, Hong and Stein (2001) find that the predictive power of past returns for skewness is larger if one considers the last six months' returns. They consider actual returns, however, and we want to partially separate bubble returns from fundamental returns. For this reason, we include the spread of the average 6-month actual gross returns over the average 6-month fundamental gross returns as a variable in the probability of being in the dormant regime. It should be expected that the larger the value of the spread, the lower the probability of the bubble continuing to be in the dormant regime. Since we examine both positive and negative bubbles, we take the absolute values of the averages before we calculate the spread. This ensures that when a negative bubble is entering the explosive state, we correctly identify the explosive 'growth' of such a bubble. Furthermore, this variable will help to identify periods of steady bubble growth when the estimated bubble deviation is arbitrarily large. This point will be elucidated shortly. In order to ensure that estimates of the probability of the dormant state are bounded between zero and one, we follow van Norden and Schaller in using a probit specification. Under this setting, the probability of being in the dormant regime in the next time period is given by:

$\operatorname{Pr}\left(W_{t+1}=D\right) \equiv n_{t}=\Omega\left(\beta_{n, 0}+\beta_{n, B}\left|B_{t}\right|+\beta_{n, S} S_{t}^{f, a}\right)$

where $\Omega$ is the standard normal cumulative density function and $S_{t}^{f, a}$ is the absolute value of the average 6-month actual returns minus the absolute value of the average 6-month returns of the estimated fundamental values.

Turning now to the probability of the bubble surviving in the explosive state $\left(q_{t}\right)$, we stated in the previous section that in the van Norden and Schaller model this probability is a function of only the absolute size of the bubble. As in most of the speculative bubble models, their approach assumes that a bubble collapse is a random event that may or may not be fuelled by the arrival of news. In effect, most rational speculative bubble models implicitly assume that investors randomly organise and decide to sell at the same time thus causing the bubble to collapse. However, although investors can estimate the probability of a bubble collapse from the size of the bubble, they still face uncertainty about the time of the collapse. We therefore conjecture that investors observe other, non-price, variables in an effort to draw inferences about the probable time of collapse, and thus to identify the optimal time to exit from the market. Our suggestion is that bubble collapses occur because investors observe a signal that leads them to the conclusion that the market is no longer expecting the bubble to continue to exist. Once they observe this signal, they start to liquidate their holdings and thus cause the bubble to collapse. We consider abnormal trading volume as a possible signal and thus as a predictor of the time of the bubble collapse.

The relationship between trading volume and stock returns has been extensively researched in the literature (see Karpoff (1987) for a meticulous survey of the literature until 1987). Ying (1966) and Morgan (1976) find that large increases in volume are usually followed by increased variance of returns, a 
result that leads Morgan (1976) to conclude that volume is associated with systematic risk. One possible explanation for this finding is that trading volume is a proxy for the degree of disagreement in the stock market ${ }^{6}$. Although Karpoff (1986) claims that abnormal volume is not proof of investor disagreement (either ex ante or ex post) about information that is available, Shalen (1993) argues that volume and return volatility have a positive relationship with the ex ante dispersion of expectations about future prices. Furthermore, He and Wang (1995) claim a high degree of uncertainty about fundamental values leads to an increase in observed trading volume. Moreover, Marsh and Wagner (2000) state that, especially for the U.S. stock market, abnormal volume can help explain increases in the size of both the negative and the positive tails of the return distribution. Although they find that this effect is symmetric, Hong and Stein (1999) and Chen, Hong and Stein (2001) claim that divergence of information, approximated by abnormal trading volume, only causes an increase in the negative tail of the future return distribution.

Based on the above, we propose that abnormally high trading volume is a signal of changing market expectations about the future of a speculative bubble. This implies that abnormal volume signals an increase in the probability of the bubble collapsing, thus causing an increase in the probability of observing a large negative (positive) return if a positive (negative) speculative bubble is present. The main difference between our model and the models of price-volume relationship described above is that the latter state that volume increases both tails of the distribution of expected returns or it signifies a decrease in the skewness of future returns. We consider abnormal volume as a sign that other investors are selling the bubbly asset ${ }^{7}$.

For abnormal volume to signal an imminent bubble collapse would require the assumption that investors have different endowments implying that there are agents in the economy that do not hold equity and may decide to do so at a future date. The effect would be the same if the number of investors changes over time. Furthermore, we assume that some investors face short selling constraints and that in the short run, the supply of equity from firms, through IPOs and SEOs is limited. The latter assumption combined with the unwillingness of investors to sell the bubbly asset because of the expectation of high returns in the surviving regime, cause the supply curve to be relatively inelastic. Under this setting, speculative bubbles are a form of 'demand side inflation' in stock prices.

As the bubble continues to grow, the probability of a crash increases and thus some investors will decide to liquidate their holdings for profit taking or because they perceive a crash to be imminent. If a sufficiently large number of investors decide to sell the bubbly asset, supply will increase significantly and thus volume will be abnormally high while the rate of increase in prices will slow. This abnormally high volume will signal that a bubble collapse is imminent. Under this setting, we model the probability of the

\footnotetext{
${ }^{6}$ The reader is referred to Harris and Raviv (1993), Kandel and Pearson (1995) and Odean (1998) for other models with the same feature.

${ }^{7}$ Abnormally high volume could also be considered a sign that investors are buying the bubbly asset.
} 
bubble continuing to be in the surviving regime $(S)$ as a negative function of both the absolute relative size of the bubble deviation, and a measure of abnormal volume:

$\operatorname{Pr}\left(W_{t+1}=S\right) \equiv q_{t}=\Omega\left(\beta_{q, 0}+\beta_{q, B}\left|B_{t}\right|+\beta_{q, B} V_{t}^{x}\right)$

where $V_{t}^{x}$ is a measure of unusual volume in period $t$.

Grouping all the equations together yields the following non-linear switching model of gross stock market returns ${ }^{8}$ :

$$
\begin{aligned}
& E\left(r_{t+1} \mid W_{t+1}=D\right)=M \\
& E_{t}\left(r_{t+1} \mid W_{t+1}=S\right)=M+\frac{\left(1-q_{t}\right)}{q_{t}}\left(M B_{t}-g\left(B_{t}\right)\right) \\
& E\left(r_{t+1} \mid W_{t+1}=C\right)=M+g\left(B_{t}\right)-M B_{t} \\
& \operatorname{Pr}\left(W_{t+1}=D\right)=n_{t} \\
& \operatorname{Pr}\left(W_{t+1}=S\right)=\left(1-n_{t}\right) q_{t} \\
& \operatorname{Pr}\left(W_{t+1}=C\right)=\left(1-n_{t}\right)\left(1-q_{t}\right)
\end{aligned}
$$

The model described by equations (11.1) through (11.6) is highly non-linear, so in order to estimate it, we linearise it by taking the first order Taylor series expansion of equations (11.1), (11.2) and (11.3) around an arbitrary $B_{0}$ and $V_{0}^{x}$. The resulting linear switching regression model of gross returns is:

$$
\begin{aligned}
& r_{t+1}^{D}=\beta_{D, 0}+u_{t+1}^{D} \\
& r_{t+1}^{S}=\beta_{S, 0}+\beta_{S, B} B_{t}+\beta_{S, V} V_{t}^{x}+u_{t+1}^{S} \\
& r_{t+1}^{C}=\beta_{C, 0}+\beta_{C, B} B_{t}+u_{t+1}^{C} \\
& \operatorname{Pr}\left(W_{t+1}=D\right)=\Omega\left(\beta_{n, 0}+\beta_{n, B}\left|B_{t}\right|+\beta_{n, S} S_{t}^{f, a}\right) \\
& \operatorname{Pr}\left(W_{t+1}=S\right)=\left(1-\Omega\left(\beta_{n, 0}+\beta_{n, B}\left|B_{t}\right|+\beta_{n, S} S_{t}^{f, a}\right)\right) \Omega\left(\beta_{q, 0}+\beta_{q, B}\left|B_{t}\right|+\beta_{q, V} V_{t}^{x}\right) \\
& \operatorname{Pr}\left(W_{t+1}=C\right)=\left(1-\Omega\left(\beta_{n, 0}+\beta_{n, B}\left|B_{t}\right|+\beta_{n, S} S_{t}^{f, a}\right)\right)\left(1-\Omega\left(\beta_{q, 0}+\beta_{q, B}\left|B_{t}\right|+\beta_{q, V} V_{t}^{x}\right)\right)
\end{aligned}
$$

We estimate the augmented model under the assumption of disturbance normality using maximum likelihood. The likelihood function of each observation is:

$$
\ell\left(r_{t+1} \mid \xi\right)=\left(1-n_{t}\right) q_{t} \frac{\phi_{S}\left(u_{t+1}^{S}\right)}{\sigma_{s}}+\left(1-n_{t}\right)\left(1-q_{t}\right) \frac{\phi_{C}\left(u_{t+1}^{C}\right)}{\sigma_{c}}+n_{t} \frac{\phi_{D}\left(u_{t+1}^{D}\right)}{\sigma_{D}}
$$

\footnotetext{
${ }^{8}$ A derivation of these equations is available from the authors upon request. The reader may also find it useful to consult to the working paper by van Norden and Schaller (1997) for a derivation of their model, which is available at the Bank of Canada web site: http://www.bankofcanada.ca/en/res/wp97-2.htm.
} 
where $\quad \phi_{S}\left(u_{t+1}^{S}\right)=\frac{\omega\left(\frac{r_{t+1}-\beta_{S, 0}-\beta_{S, B} B_{t}-\beta_{S, V} V_{t}^{X}}{\sigma_{S}}\right)}{\sigma_{S}}, \quad \phi_{C}\left(u_{t+1}^{C}\right)=\frac{\omega\left(\frac{r_{t+1}-\beta_{C, 0}-\beta_{C, B} B_{t}}{\sigma_{C}}\right)}{\sigma_{C}}, \quad$ and $\phi_{D}\left(u_{t+1}^{D}\right)=\frac{\omega\left(\frac{r_{t+1}-\beta_{D, 0}}{\sigma_{D}}\right)}{\sigma_{D}}$ denote the probability density functions of an observation conditional on it being generated by a given regime. $\omega$ is the standard normal probability density function (pdf), $\sigma_{D}, \sigma_{S}$, $\sigma_{C}$ are the standard deviations of the disturbances in the dormant, surviving and collapsing regimes respectively. In order to estimate the model, we directly maximise the above log-likelihood function using a constrained optimisation algorithm. The only constraint imposed is that the standard deviations of the residuals are positive, thus bounding the log likelihood function away from infinity ${ }^{9}$.

From the Taylor series expansion, several testable implications can be derived concerning the sign and / or size of the coefficients of the state equations. These conditions should be satisfied if the three-regime model of speculative bubbles has explanatory power for gross returns, and are:

$$
\begin{aligned}
& \beta_{C, B}<0 \\
& \beta_{S, B}>\beta_{C, B} \\
& \beta_{S, V}>0 \\
& \beta_{q, B}<0 \\
& \beta_{q, V}<0 \\
& \beta_{n, B}<0 \\
& \beta_{n, S}<0
\end{aligned}
$$

Restriction (i) states that as the bubble increases in size, the expected returns in the collapsing regime should decrease (increase) if a positive (negative) bubble is present, since the bubble must collapse in regime $(C)$. Furthermore, the speculative behaviour model implies that restriction (ii) must hold since as the bubble increases in size we expect the difference of expected returns across the surviving and the collapsing regimes to increase as well. Restriction (iii) states that the expected returns in the surviving regime must increase if abnormal volume is observed since it signals an increase in the probability of a bubble collapse. Restrictions (iv) and (v) should hold if our speculative behaviour model is valid since the probability of the bubble surviving must decrease when the absolute size of the bubble or abnormal volume in the market increase. The same holds for restrictions (vi) and (vii) because the probability of being in the dormant regime $(D)$ must decrease as the bubble grows larger in absolute size or the returns of the market in the last 6 months are larger than the returns on the fundamental values.

\footnotetext{
${ }^{9}$ Note that the log-likelihood function is unbounded if the standard deviations of the error terms in the three regimes become
} 
In order to test the power of the model to capture bubble effects in the returns of the S\&P 500, we follow van Norden and Schaller (1999) and test the three-regime speculative bubble model against two alternative models that are nested within the model of speculative behaviour. These alternative models capture stylised facts of stock market returns and therefore we examine whether our model has any explanatory power beyond these simpler specifications. Firstly, we examine whether the effects captured by the switching model can be explained by a more parsimonious model of volatility regimes. In order to test this, we examine the following conditions:

$$
\begin{aligned}
& \beta_{D, 0}=\beta_{S, 0}=\beta_{C, 0} \\
& \beta_{S, B}=\beta_{C, B}=\beta_{S, V}=\beta_{q, B}=\beta_{q, V}=\beta_{n, B}=\beta_{n, S}=0 \\
& \sigma_{D} \neq \sigma_{S} \neq \sigma_{C}
\end{aligned}
$$

Restriction (14.1) implies that the intercepts across the three state equations are the same while restriction (14.2) states that the bubble deviations, the measure of abnormal volume and the measure of the spread of actual returns above the fundamental returns have no explanatory power for the returns of period $t+1$ or for the probability of switching regimes. The later point suggests that there is a constant probability of switching between a low, medium and high variance regime as this is stated in restriction (14.3).

The volatility regimes model examines the joint hypothesis that the intercepts are the same across the three regimes and that returns and the generating state of returns are unpredictable if we use the variables under consideration. It is interesting to separate the two hypotheses and to examine whether returns can be characterised by a simple mixture of normal distributions model that allows both returns and variances to differ across the three regimes. This mixture of normals model implies the following restrictions:

$$
\beta_{S, B}=\beta_{C, B}=\beta_{S, V}=\beta_{q, B}=\beta_{q, V}=\beta_{n, B}=\beta_{n, S}=0
$$

Finally, we augment the original vNS model into a three-regime model of speculative behaviour that does not include the measure of abnormal volume and the spread of returns in the state or transition equations (hereafter referred to as the AvNS model). If these volume and spread variables have explanatory power for the next period's returns, the test should reject this simpler specification. The restrictions of this last test are:

$$
\beta_{S, V}=\beta_{q, V}=\beta_{n, S}=0
$$

\section{DATA AND FUNDAMENTAL VALUES}

The data we use to test for the presence of speculative bubbles are 1381 monthly observations on the S\&P 500 for the period January 1888 - January 2003. In order to calculate fundamental values and real gross returns, we use data taken from Shiller $(2000)^{10}$. The measure of monthly abnormal volume is calculated

\footnotetext{
zero.

${ }^{10}$ Data available at: http://www.econ.yale.edu/ shiller/data.htm. For a description of the data used see also Shiller (2000) and the description online. Shiller's sample ends in January 2000, but we update his sample until January 2003 using data obtained
} 
as the monthly average of daily share volume, reported by the $\mathrm{NYSE}^{11}$, and then the percentage deviation of last month's volume from the 6 month moving average is taken ${ }^{12}$. This moving average is constructed using only lagged volume figures that would have been included in agents' information sets. The monthly dividend and price series are transformed into real variables using the monthly U.S. Consumer Price - All Items Seasonally Adjusted Index reported by Shiller (2000). Finally, as noted earlier, the spread between actual and fundamental returns $\left(S_{t}^{f, a}\right)$ is calculated as $S_{t}^{f, a}=\left|r_{t}^{a, 6}\right|-\left|r_{t}^{f, 6}\right|$, where $r_{t}^{a, 6}$ is the average 6month actual returns and $r_{t}^{f, 6}$ is the average 6-month returns of the estimated fundamental values.

In order to construct fundamental values, we follow van Norden and Schaller (1999) and use a mathematical manipulation of Campbell and Shiller's (1987) VAR model of the dividend component of prices. The Campbell and Shiller model allows for predictable variation in the dividend growth rate, although it assumes constant discount rates. ${ }^{13}$ The Campbell and Shiller model states that the spread between stock prices and a constant multiple of current dividends is the optimal forecast of a multiple of the discounted value of all future dividend changes:

$$
s_{t} \equiv p_{t}^{f}-\frac{1+i}{i} d_{t}=\frac{1+i}{i}\left(\sum_{g=1}^{\infty} \frac{1}{(1+i)^{g}} E_{t}\left(\Delta d_{t+g}\right)\right)
$$

Using the VAR methodology created by Campbell and Shiller, we examine whether changes in dividends can be forecasted by the spread between prices and the multiple of current dividends. If the changes in dividends cannot be forecasted by the spread, this would imply that investors use only past dividends to form expectations about future dividends. If, on the other hand, investors include other variables in their information set then this information will be reflected in past prices and thus past realisations of the spread. This would imply that the spread has power to forecast future dividend changes. Under this approach, the measure of relative bubble size is thus given by:

$$
B_{t}=1-\frac{s_{t}+\left(\frac{1+i}{i}\right) d_{t-1}}{p_{t}}
$$

Figure 1 presents the bubble deviations calculated from equation (18) for the entire sample (after adjusting for the number of lags). Note that the bubble deviations are increasingly large in 1929, 1987 and the late 1990's. The bubble deviations are significantly negative in 1917, 1932, 1938, 1942 and 1982. Overall, the Campbell and Shiller measure of bubble deviations displays significant short-term variability but also large and persistent broad swings.

\footnotetext{
from Datastream. In order to verify that the two datasets are consistent, we compare Shiller's data from January 1965 to January 2000 with the values from Datastream and find no differences.

${ }^{11}$ Data available at: http://www.nyse.com/marketinfo/marketinfo.html.

${ }^{12}$ We also examined unusual trading volume measures using 3,12 and 18 month moving averages but found that the deviation from the 6-month moving average has the highest explanatory power in predicting both the level and the generating state of returns. The results for the other measures of abnormal volume are not presented for brevity and are available upon request from the authors.

${ }^{13}$ We also examined a simple dividend multiple measure of fundamentals and found that our results are qualitatively unchanged. The results are not presented here for brevity but can be provided in the form of an appendix from the authors upon request.
} 


\section{RESULTS}

The results of the three-regime model of speculative behaviour are presented in the first part of Table 1 alongside the results of the vNS model, and the AvNS model for comparison. The AvNS model is a 3regime extension of the van Norden and Schaller model that is equivalent to our three-regime model but does not contain any additional variables other than the bubble deviations in the state and transition equations. The second panel of the table contains the results of the likelihood ratio (LR) tests of the restrictions on the coefficients implied by the speculative behaviour model while the third panel of Table 1 presents the results of the likelihood ratio tests of the volatility regimes, mixture of normals, and the extended van Norden and Schaller alternative models.

From the first part of Table 1, all the coefficients of the three-regime model have the expected sign and a financially meaningful magnitude. More specifically, the estimate of the intercept in the dormant regime $\left(\beta_{D, 0}\right)$ is 1.0031 , and it is highly significant as seen from the standard error. This implies that the expected return in the dormant regime, which is equal to the required fundamental return, is $0.31 \%$ per month (3.78\% on an annual basis). We consider this figure reasonable in terms of real 'fundamental' returns, and the corresponding value of this coefficient for the AvNS model is quite similar (1.0033), implying a mean return in the surviving regime of $4.03 \%$ on an annual basis.

However, when the price series enters the explosive regime, its behaviour becomes more extreme. The equilibrium gross return in the surviving regime $\left(\beta_{S, 0}\right)$, when the bubble size and the measure of abnormal volume are equal to zero, is significantly higher than in the dormant regime, $1.18 \%$ per month ( $15.12 \%$ on an annualised basis. The equilibrium return in the surviving state in the vNS model is between the equilibrium returns of the dormant and the surviving regimes in the three-regime models. This could be evidence that the equilibrium return in the two-regime model is the result of the mixture of the dormant and explosive growth regimes. Turning now to the equilibrium return in the collapsing state, we can see that the expected equilibrium return in state $C$ for the three-regime model is $-2.16 \%$ per month $(-23.09 \%$ on an annualised basis). This is consistent with the theory of speculative bubbles since the expected return in the collapsing state should be negative.

Examining the slope coefficients in the state equations, we note that the coefficients on the relative bubble size in the surviving and the collapsing regimes $\left(\beta_{S, B}\right.$ and $\left.\beta_{C, B}\right)$ have the expected signs ${ }^{14}$ and are statistically significant at the $1 \%$ level. The speculative bubble model requires the return in the collapsing

\footnotetext{
${ }^{14}$ It is not possible to derive an expected sign for the bubble coefficient in the surviving state since the speculative bubble model only implies that it should be greater in value than the bubble coefficient in the collapsing regime. Nevertheless, we should expect that as the bubble increases in size, investors demand a higher return to compensate them for the increased risk of bubble collapse.
} 
regime to be a negative function of the size of the bubble $\left(\beta_{C, B}<0\right)$ while the coefficient of the bubble size in the surviving regime must be greater than the corresponding coefficient in the collapsing regime $\left(\beta_{S, B}>\beta_{C, B}\right)$. From the second panel of Table 1, we can see that both of these conditions for model plausibility are supported by the data. The null hypothesis that the bubble coefficient in the collapsing regime is equal to zero is rejected at the $5 \%$ level ( $p$-value of LR test 0.02 ), implying that as the bubble size increases, the returns in the collapsing regime decrease ${ }^{15}$. Furthermore, we can see that restriction (ii) is satisfied since $\beta_{S, b}>\beta_{C, b}$ at the 5\% level (in the second panel of Table 1 the $p$-value of the LR test is $0.019)$.

The three-regime model also incorporates abnormal volume in the surviving state equation. The point estimate of the abnormal volume coefficient in the surviving state $\left(\beta_{S, V}\right)$ is statistically significant $(p$ value 0.0061 ), and has the expected sign according to condition (iii) ( $\beta_{S, V}>0$ at the $10 \%$ significance level). This implies that as volume increases, expected returns for the next period increase, consistent with our conjecture that increased abnormal volume signals increased risk.

The coefficient estimates of the equation for the probability of being in the steady growth regime, equation (23.4), are in favour of the three-regime speculative behaviour model. For the three-regime model, the intercept coefficient $\left(\beta_{n, 0}\right)$ implies that there is a $15.43 \%$ probability of switching to the explosive state when the size of the bubble and the spread of actual returns are both equal to zero. This probability is calculated as $1-\Omega\left(\beta_{n, 0}\right)$ using the point estimates shown in Table 1 . The corresponding probability for the AvNS model is $13.83 \%$. However, as the bubble grows, the probability of being in the dormant state in period $t+1$ decreases since the coefficients on the absolute bubble size and the spread of returns are negative. More specifically, the point estimate of the coefficient on the absolute bubble size in the equation for the probability of the dormant regime $\left(\beta_{n, B}\right)$ is -0.3806 and is significant at the $5 \%$ level. This implies that as the bubble grows in size, the probability of being in the explosive regime increases ${ }^{16}$.

Our model also incorporates the spread of the average six-month actual returns over the six-month average of fundamental returns in the transition equation. This variable helps to distinguish periods of explosive growth, especially when the estimated bubble deviations are large. The coefficient estimate on the measure of the spread $\left(\beta_{n, S}\right)$ is negative, as expected, and significant at the 5\% level. Furthermore, the

\footnotetext{
${ }^{15}$ The opposite holds for negative bubbles since they collapse by yielding positive abnormal returns, although it would require a negative bubble size in excess of $-15 \%$ in order for the returns of the collapsing regime to become positive.

${ }^{16}$ Although the unconditional probability of enterning the exposive state is quite low, it is of interest to consider the cumulative effect that this could have over a period of time. For example, the probability of remaining in the dormant state for the next six months would be equal to $36.7 \%$, and would be given by $\left(1-\left(1-\Omega\left(\beta_{n, 0}\right)\right)\right)^{6}$
} 
LR test results show that the conditions on the signs of the coefficients in the transition equation (vi) and (vii), are satisfied at the $1 \%$ and $5 \%$ level respectively as seen from part two of Table 1 . The LR test rejects the hypothesis that the spread of actual returns does not affect the probability of being in the dormant regime and confirms that the probability of constant growth decreases as the bubble growth accelerates.

Turning now to the probability of being in the surviving regime, the coefficient estimates of the classifying equation (12.5) for the three-regime model and for the AvNS model are in favour of the presence of periodically collapsing speculative bubbles. As the bubble grows, the probability of being in the surviving regime in period $t+1$ decreases since the coefficient on the absolute bubble size is negative (2.0291) and statistically significant at the $1 \%$ level. Furthermore, the LR test shows that condition (iv), which states that this coefficient should be negative $\left(\beta_{q, B}<0\right)$, is satisfied at the $10 \%$ level. This is consistent with Evans (1991) and the notion that when the bubble is relatively small, the probability of the bubble collapsing is small and thus investors do not take it into account in the pricing of the asset. As the bubble grows and / or abnormal volume increases, the probability of the bubble collapsing increases geometrically. The point estimate of the abnormal volume coefficient in the equation for the probability of survival $\left(\beta_{q, V}\right)$ is negative, as expected, and statistically significant (-6.1212 with $p$-value 0.0001$)$. The LR test confirms that the probability of the bubble continuing to grow with explosive expectations is a negative function of abnormal volume. From the above, the probability of the bubble collapsing should increase significantly prior to a bubble collapse if our three-regime model is superior at forecasting regime changes. Indeed, in August 1982 when a large negative bubble is present, the probability of the bubble collapsing, estimated from the three-regime model, increases by $530 \%$ to a value of $2.08 \%$. The AvNS model, predicts, for the same month, a probability of collapse of $2.22 \%$, which is only $1.3 \%$ higher than for the previous month.

The probabilities of being in a given regime calculated from the point estimates of the three-regime model are presented in Figure $2^{17}$. The corresponding probabilities from the AvNS model are presented in Figure 3. It is apparent that the three-regime model incorporating the volume and spread variables yields a more variable probability of being in the steady growth regime, which decreases considerably during periods of significant market advances or declines. Furthermore, the probability of being in the collapsing regime increases significantly before several bubble collapses, namely August 1929, June 1932, August 1982 and October $2000^{18}$.

17 These probabilities are calculated as $\operatorname{Pr}\left(W_{t+1}=D\right)=n_{t}, \quad \operatorname{Pr}\left(W_{t+1}=S\right)=\left(1-n_{t}\right) q_{t}$, and $\operatorname{Pr}\left(W_{t+1}=C\right)=\left(1-n_{t}\right)\left(1-q_{t}\right)$ using the point estimates of Table 1 .

18 Note that some of these periods were followed by market rallies. This is because we are also examining price decreasing bubbles, which collapse yielding positive returns. The probabilities of collapse for both models are also high in other periods that were not followed by bubble collapses. This could be evidence against the speculative bubble model. However, we will show in the next section that the three-regime bubble model has significant predictive ability and can be used to time market reversals. 
The standard deviations of the residual terms from the three-regime model are consistent with the theoretical predictions since the standard deviation of the error term in the collapsing regime is greater than in the surviving regime. This is because bubbles often collapse by yielding extreme negative returns (or positive returns in the case of price decreasing bubbles). Furthermore, according to Evans (1991) and van Norden and Vigfusson (1998), the standard deviation of the errors in the dormant regime should be small, since it is periodically collapsing speculative bubbles that cause an increase in the variance of returns. The standard deviation of the residuals in the steady growth regime is $2.95 \%$, in the surviving regime it is $4.71 \%$, while in the collapsing regime it is $10.91 \%$ on a monthly basis.

The third panel of Table 1 presents the results of the LR tests of the augmented model against simpler models that capture well-documented properties of stock market returns. The LR test result rejects the volatility regimes alternative specification at the $1 \%$ level implying either that the mean returns are different across the three regimes, or that speculative bubbles, abnormal volume and the spread of actual returns have predictive power for the returns of period $t+1$ or for the probability of switching regimes. In order to separate the two restrictions, we test the speculative behaviour model against a mixture of normal distributions model and the result of the LR test shows that the data reject the mixture of three normal distributions alternative in favour of the three-regime periodically collapsing speculative bubble model. This suggests that the measure of bubble deviations, the measure of abnormal volume and the spread of actual returns have significant forecasting ability for next period returns and for the probability of switching regimes. The LR test statistic signifies a rejection of the null of the mixture of normal distributions at the $1 \%$ significance level. We also examine the three-regime model against the AvNS model in order to see whether abnormal volume and the spread of actual returns should be used in order to forecast the level and the generating state of returns. Again, our model rejects this simpler specification.

\section{Predictive and Profitability Analysis}

Although in the previous section we showed that the three-regime speculative behaviour model has significant explanatory power for the S\&P 500 returns, the ability of this model to forecast historical bubble collapses has not yet been examined. In a previous study, van Norden and Vigfusson (1998) examined the size and the power of bubble tests based on regime switching models, and found that the tests are conservative, but have significant power in detecting periodically collapsing speculative bubbles of the form described in Evans (1991). However, their technique only examines the econometric reliability of the switching speculative bubble model developed by van Norden and Schaller.

In this section, we will examine the out of sample forecasting ability of the three-regime model and compare it with the forecasting ability of the vNS and the AvNS models. We will then investigate whether regime switching speculative behaviour models can be used to determine optimal market entry and exit 
times. We do this by creating trading rules based on inferences from the speculative behaviour models and test whether such rules can yield abnormal trading profits. Until now, all of the bubble tests that have been created have, to our knowledge, only addressed the problem of bubble identification. We follow a different approach and examine whether inferences from speculative behaviour models can be used in order to make financially meaningful forecasts. This approach will also help examine the predictive ability of our model against that of van Norden and Schaller's models, in a financially intuitive way ${ }^{19}$.

In the formulation of the trading rules, we ensure that only information that would have been available to investors at the time that trades were made is used. For this reason, we cut our sample approximately in half, and estimate the three speculative behaviour models using data from January 1888 to December 1945. This provides us with initial estimates of the apparent bubble deviations, the expected returns and the probabilities of being in the three regimes for January 1946. Using the point estimates of the three models, we can then calculate the conditional probability of an unusually low and of an unusually high return in the next period (January 1946). The sample is then updated by one observation with the models and the probabilities of a crash and of a rally re-estimated. We continue in this fashion and update the sample period used by one month until the end of the sample (January 2003) is reached.

We consider both the probability of a crash and of a rally to allow for positive and negative bubbles. Using this rolling estimation with a fixed starting point, we form forecasts for the conditional probabilities of a crash and of a rally using only information that is available to investors up to that point in time. The conditional probability of a crash is calculated using the following equation:

$\operatorname{Pr}\left(r_{\mathrm{t}+1}<K\right)_{t}=n_{t} \omega\left(\frac{K-\beta_{D, 0, t}}{\sigma_{D, t}}\right)+\left(1-n_{t}\right)\left[q_{t} \omega\left(\frac{K-\beta_{S, 0, t}-\beta_{S, B, t} B_{\mathrm{t}}-\beta_{S, V, t} V_{t}^{X}}{\sigma_{S, t}}\right)+\left(1-q_{t}\right) \omega\left(\frac{K-\beta_{C, 0, t}-\beta_{C, B, t} B_{\mathrm{t}}}{\sigma_{C, t}}\right)\right]$

where $\quad n_{t}=\Omega\left(\beta_{n, 0, t}+\beta_{n, B, t}\left|B_{t}\right|+\beta_{n, S, t} S_{t}\right), \quad$ and $\quad q_{t}=\Omega\left(\beta_{q, 0, t}+\beta_{q, B, t}\left|B_{t}\right|+\gamma_{q, V, t} V_{t}^{x}\right)$. The time subscripts attached to the speculative model coefficients denote the estimated values of the coefficients using data only up to and including time $t$. In (19), $K$ is the threshold below which a return is classified as a crash and this is defined as $K=\mu_{t}-2 *\left(\sigma_{r, t}\right)$, where $\mu_{t}$ is the mean of past gross returns until time $t$, and $\sigma_{r, t}$ is the standard deviation of past gross returns until time $t$. The conditional probability of observing an extreme positive return of at least two standard deviations above the mean of past returns in period $t+1$ can be defined accordingly.

\footnotetext{
${ }^{19}$ Several studies have shown that excess stock market returns are partially predictable. One possible explanation is the time variation of required rates of returns. An alternative explanation is offered by Poterba and Summers (1988) who claim that bubbles or fads can induce predictability of excess returns. Note that in this study we are not trying to predict excess returns. We focus our effort in predicting the generating state of returns in the next time period, using observable variables. If the generating state of returns can be predicted then an investor can earn abnormal returns by timing bubble collapses. If our model has no out of sample forecasting ability over the level or the generating state of returns in the next time period then this could be taken as
} 
The probabilities of a crash calculated using the three-regime model and using the vNS model are presented in Figure 4 together with markers to signify the 20 largest negative 1-month and 3-month returns observed for the $\mathrm{S} \& \mathrm{P} 500^{20}$ in the following month. In the top part of the figure, we plot the logarithm of the real S\&P 500 index and the logarithm of the Campbell and Shiller (1987) fundamental values. From Figure 4, it is evident that the probability of a crash increases during several periods when a bubble is suspected to be present but more importantly it is high before several of the 20 largest 1-month declines of the S\&P 500 including 1959, 1961, 1970, 1974 and 2000. All of these periods are followed by a strong correction in stock price levels.

In Figure 5, we present the conditional probability of a rally calculated from the three-regime model and from the vNS model with markers to signify the 20 largest 1-month, 3-month and consecutive market advances $^{21}$. It is clear that the probability of a rally increases dramatically during several periods when a negative bubble appears to be present, especially in 1949-1950 and 1982. Again, the probability of a rally estimated from the three-regime model is significantly more variable than the corresponding probability derived from the vNS model.

However, there are several periods during which both probabilities increase simultaneously, thus damping the effects we seek to observe, namely the conditional probability of a crash and of a rally in the next period. This is because the conditional distribution of expected returns is a mixture of a low variance (dormant state), medium variance (surviving state) and a high variance (collapsing state) distribution. As the relative size of the bubble increases, the weight of the high variance distribution increases and thus both tails increase at the same time. Furthermore, we note several spikes in the probabilities of a crash and of a rally that where not immediately followed by a market collapse or a market rally. This is what we would expect to see from a model of speculative behaviour, since if the time of the crash could be forecasted with great accuracy then this would violate the assumption of investor rationality, since if an investor knows that the bubble will collapse in a month he will sell now or at any point until the time of collapse. This would rule out speculative bubbles all together since actual prices could never deviate from fundamental values in this setting.

We proceed to form a trading rule based on the models and to calculate the risk and return of these rules at each point in time. We then evaluate the trading rules' results by calculating the profits (or losses) that an investor would have made if he were using the three-regime model in an effort to time large market

evidence against the presence of bubbles, against our specific speculative behaviour model, or alternatively as evidence in favour of market efficiency.

${ }^{20}$ At this point, it should be noted that we have allowed for partial collapses in the specification of the bubble model and therefore a bubble may partially collapse for several periods before starting to grow again. For this reason, we also examine the probability of a crash (rally) against the top 203 -month negative returns as well as the top 20 draw-downs. A draw-down is defined as the cumulative return from the last local maximum to the next local minimum of the S\&P 500 Index and thus refers to cumulative continuous losses. 
movements from January 1946 to January 2003 and compare the returns to the results of the vNS model and with returns generated by random trading rules. The trading rule states that when the probability of a crash (rally) crosses the upper $90^{\text {th }}$ percentile ${ }^{22}$ of its historical values, the investor should sell (buy) the index, investing entire wealth in a risk free asset (equities) ${ }^{23}$, and maintain this position until the probability of a crash (rally) becomes lower than its historical median value, i.e. until the bubble deflates $^{24}$. When the appropriate probability becomes lower than its historical median value, entire wealth should be invested in the S\&P 500 Index. We include the probability of a rally in the strategy since an investor should buy if there is a negative bubble and the probability of a rally is greater than the $90^{\text {th }}$ percentile of its historical values. In order to ensure that we are not using any information that was not available to the investor at the time of the trade, we calculate the median value and the top $90^{\text {th }} \%$ value using a rolling window with a fixed starting point in January 1888.

We compare the three-regime model with the vNS model by calculating the total holding period return for every month and examine the mean, standard deviation, skewness and kurtosis of each trading rule's return distribution. We note the number of trades that the rule has generated over the trading period in order to adjust trading profits for transaction costs, and we also note the percentage of time that an investor following the rule would have invested in equities. To take into account transaction costs, we assume a $0.5 \%$ round trip $\operatorname{cost}^{25}$. We then compare the trading performance of the three-regime model with the results of the vNS model and with the results of a simple buy and hold strategy.

Furthermore, in order to examine the statistical significance of the profits generated from the trading rule, we form 10,000 long random trading rules created by randomly generating series of zeros and ones, the length of which is equal to the number of months in our trading sample (January 1946-January 2003, or 685 months) using a binomial distribution. The probability of success (i.e. of a binomial draw of one) is set equal to the percentage of time that trading rule would suggest the investor to be in the market. We use this probability of success because it yields random trading rules with comparable average holding periods to our trading rules. In order to test for the statistical significance of the bubble rules, we compare the returns and the other moments of the returns' distributions with those of the random rules and if our model yields a profit larger than $90 \%, 95 \%$ or $99 \%$ of the random trading rules we can conclude that our

\footnotetext{
${ }^{21}$ The 20 largest consecutive market advances ('draw-ups') are defined as the 20 largest consecutive positive returns, defined as the return from the last local minimum to the next local maximum.

${ }^{22}$ Focusing on the $90^{\text {th }}$ percentile is somewhat arbitrary, but represents a trade-off between using too high a cut-off, which will encourage the investor to remain in the market when the bubble has a historically high probability of collapse, while using too low a cut-off will lead the investor out of the market too frequently, resulting in missed bull market opportunities. Our results are not qualitatively altered if an $80 \%$ or $95 \%$ cut-off is employed instead.

${ }^{23}$ The risk free rate for the period January 1946 to January 2003 is taken to be the monthly continuously compounded yield on 3-Month Treasury Bills. The data are taken from the Federal Reserve Bank of St Louis web site http://www.stls.frb.org/fred/data/irates.html.

${ }^{24}$ We use the median in order to avoid any unwanted influence from extraordinarily large probabilities of a crash and of a rally observed during the sample period (especially 1929-1933).

${ }^{25}$ It should also be noted that the use of our trading rule may have adverse tax effects as a result of the realisation of capital gains, and therefore that the rule and the trading return results described are more relevant to tax-sheltered accounts that do not have such tax liabilities.
} 
abnormal profits are statistically significant at the $10 \%, 5 \%$ and $1 \%$ levels respectively. Finally, for every trading rule generated from the bubble models and the random rules, we calculate the wealth that an investor would have accumulated by January 2003 from an initial investment of one dollar in January 1946.

Table 2 contains the trading rule results for the three-regime and for the vNS models, and also presents the results of the buy and hold strategy. The values in parentheses are the percentage of random rules that lead to higher average returns, lower standard deviation, higher skewness etc. Lower values inside parentheses denote a more superior relative performance of the speculative behaviour model trading rule against the random trading rules.

From the results, we see that the three-regime model trading rule yields higher Sharpe ratios and a larger end of period wealth compared to the vNS model. More specifically, if an investor used the three-regime speculative behaviour model with the Campbell and Shiller (1987) measure of fundamental values throughout the period examined, he would have received an average return of $0.66 \%$ per month $(8.2 \%$ on an annualised basis) with a standard deviation of $2.41 \%$. If, however, the investor used the vNS model, he would only receive an average return of $0.39 \%$ per month with a standard deviation of $2.10 \%$. Furthermore, the end of period wealth for the three-regime model is consistently higher than that of the original vNS model, and the buy and hold strategy.

The three-regime model also clearly outperforms $99 \%$ of the randomly generated trading rules in terms of the Sharpe ratio and end of period wealth, signifying that the three-regime model has significant market timing ability. Application of the vNS model only manages to beat $35 \%$ of the randomly generated trading rules in end of period wealth and $45 \%$ of the random strategies in terms of the Sharpe ratio. Moreover, the end of period wealth and the Sharpe ratio of the three-regime model trading rule is higher than the Sharpe ratio of the buy and hold strategy, although this superiority with respect to the buy and hold strategy fades somewhat if we examine the total wealth and the Sharpe ratio after we take into account the transaction costs involved. Note that the three-regime model requires considerably higher number of trades than the original van Norden and Schaller model.

This higher end of period wealth of the three-regime model is achieved with higher skewness and lower kurtosis coefficients than the vNS model. Both of these higher moments of the distribution (i.e. the third and fourth moments) of the three-regime model returns would be more desirable to investors under some fairly weak assumptions concerning the shape of investor utility functions (see Scott and Horvath (1980) 
for higher moment preferences and Kraus and Litzenberer (1976) and references therein for skewness preference in asset pricing) ${ }^{26}$.

The above results show that if an investor used the three-regime model to identify optimal market entry and exit points, he would have earned a higher Sharpe ratio and end of period wealth in January 2003 than if he was using the vNS model or following a passive buy and hold strategy. In Figure 6, we plot the real S\&P 500 Composite Index and the net excess wealth of the three-regime model trading rule as a percentage of the wealth of the buy and hold strategy. On the plot of the S\&P 500, we place markers that signify entry and exit times that the three-regime model trading rule has generated. In this figure, investor wealth has been adjusted for transaction costs assuming a $0.5 \%$ round trip cost paid upon exit from the market. This could be considered low for the earlier period of the sub sample, although since the 1970's, investors have been able to trade in index tracking funds at a much lower transaction cost (for example, the Vanguard S\&P500 tracker index fund currently has an expenses ratio of $0.18 \%$ ). Therefore we argue that $0.5 \%$ should be a representative average figure for the entire sample; in fact, any transaction cost below $1.3 \%$ leads the trading rule from our 3-regime model to outperform the buy-and-hold strategy in net terms.

From the figure, it is evident that the three-regime model leads to profitable trades although sometimes it forces the investor to be out of the market for long periods of time (especially in the 1950's, early 1980's and the 1990's). Nevertheless, it produces higher wealth than the buy and hold strategy at the end of the sample. Note however, that at the end of the sample, the three regime model trading rule looses much of its superiority since it forces the investor to be out of the market from the mid 1990's and the large observed bubble deviation does not reverse until the end of the sample. However, we can see that in the late 1960's and 1970's our model issues a sell order in advance of many market declines and this leads to a higher end of period wealth than the buy and hold strategy in 1974. This superiority is maintained until 1995 when the model orders the investor to leave the market. At the end of the sample our model orders us to be out of the market until September 2001, thus preserving some wealth, although we re-enter the market too early. There are a number of possible reasons for this. It is possible, for example, that a bubble of the form assumed was not present in the data at the end of the sample period or it is possible that the model used to estimate fundamental values is not adequate and does not capture fundamentals precisely.

\section{CONCLUSIONS}

In this study we have presented a three-regime switching speculative behaviour model that is able to capture speculative dynamics present in the S\&P 500 Composite Index. The model is based on the models

\footnotetext{
${ }^{26}$ This arises since rational investors desire high positive values of odd moments (i.e. mean and skewness) and the smallest possible values of even moments (variance and kurtosis). Intuitively, skewness measures the relative size of the left-hand tail of the return distribution, and a large left tail implies a greater probability of large losses. Similarly, kurtosis is a measure of tailfatness and, all other things being equal, a large kurtosis again implies a higher probability of large losses.
} 
developed by van Norden and Schaller (1999) and Evans (1991). We show how the original van Norden and Schaller model can be augmented to include a third regime in which the bubble grows at the fundamental rate of return. In this dormant state, the bubble behaviour is very different than in the explosive state since the probability of collapse is negligible. We show that, as in van Norden and Schaller, the magnitude of the difference between actual prices and fundamental values is a significant predictor and classifier of returns. Furthermore, we show that other variables such as abnormally high volume and the difference of average actual returns from average fundamental returns can assist in classifying future returns into the three regimes.

Using data on the S\&P 500 for the period January 1888 - January 2003, we find that the speculative behaviour model has significant explanatory power for the next month's returns. More specifically, as the bubble grows in size and yields higher returns, the probability of being in the explosive regime in the next time period increases, and thus the expectation of bubble growth is adjusted to compensate for the now higher probability of a bubble collapse. In the explosive state, the size of the bubble deviation and the measure of abnormal volume help in identifying the probability of observing a bubble collapse. We find that the probability of observing an extreme negative return, of at least two standard deviations below the historical mean of returns, increases significantly when a positive bubble is present and abnormal volume is high. When the three-regime model is tested against more parsimonious and established alternatives such as mixtures of normal distributions, volatility regimes and a three-regime extension of the original model of van Norden and Schaller, it appears that our model's specification captures additional information present in the data and classifies returns in the switching regime framework more effectively.

We test the out-of-sample forecasting ability of the three-regime model and of the van Norden and Schaller model in a financially intuitive way by constructing trading rules based on inferences concerning the conditional probability of a crash and of a rally, and analysing the returns obtained with the use of the original two regime speculative behaviour model and of our three-regime extension. We examine the timing ability of the bubble models by comparing the returns of the speculative bubble model trading rules with the returns on 10,000 randomly generated trading rules that have the same average proportion of the sample period invested in equities. We find that the three-regime model can consistently lead to higher Sharpe ratios than the vNS model, the randomly generated trading rules, and the buy and hold strategy, although some of this superiority fades when we take into account the transactions costs involved. Thus, whilst our model is not a "money machine", its usefulness lies in helping to protect investors from downside risk if they are willing to pay the associated transactions costs, akin to the purchase of a protective put. Nevertheless, we must note that there are several limitations of the switching regime speculative bubble models employed here and elsewhere, which provide scope for further research.

First, although the speculative behaviour models presented are considered as direct tests for the presence 
of periodically collapsing speculative bubbles, in effect they examine the presence of a particular form of regime switching behaviour dictated by simple models of collapsing speculative bubbles. It is possible that this regime switching behaviour may be caused by expected shifts in the evolution of fundamentals that are not realised or any other factor that causes regime switching in asset returns (van Norden and Vigfusson (1998)). However, this is the problem of any parametric econometric model: the behaviour of a dependent variable that the econometrician attributes to a particular variable may be caused by another unobservable variable.

Furthermore, although we allow for the time variation of the dividend growth rate, we assume that the discount rate is constant in the construction of fundamental values. However, the time variation of expected returns has been well documented and thus it would be interesting to determine whether speculative behaviour models are robust against specifications of fundamentals that allow for predictable variation in the discount rate. Moreover, our fundamental values are dividend based and there is evidence that companies in the 1990's have shifted to low dividend payout policies. This could be a contributory factor in the development of the apparently large bubble deviation estimated in the late 1990's. It is also worth noting that anecdotal evidence suggests that when a new sector appears in the economy, stock markets display significantly higher growth relative to dividend-based fundamentals ${ }^{27}$. However, when these new sectors become mature, stock market prices appear to revert back to their dividend-based fundamentals.

Models of the form developed here could find a number of useful applications in other areas of finance. Regime-switching speculative behaviour models could be used, for example, in portfolio construction or in the computation of value at risk (VaR). The academic literature on the latter is now large and well developed - see, for example, Billio and Pelizzon (2000), who employ a multivariate regime switching approach to calculate accurate value at risk estimates for Italian stocks, or Jorion (2000) and the references therein. Value at risk essentially involves an estimation of the cost of extreme losses that occur with a certain probability (e.g., 1\%), and our model could be used in such calculations. It would also be of interest for future research to examine the accuracy of the forecasts of the density of returns using the probability integral transform.

\footnotetext{
${ }^{27}$ Zeira (1999), presents a model of stock market booms and crashes caused by the uncertainty investors face about fundamental values. In effect, market booms are caused by informational overshooting when new technologies are implemented in the production process and the limit of such technologies is unknown. Once the limit of this 'new' technology is reached, market participants realise that no further growth is possible and thus cause market prices to crash. This model can be transformed to explain market booms and crashes using the arrival of new investors to the market ('greater fools') or the liberalisation of monetary policy by central banks. Zeira claims that this model is capable of partly explaining the booms and crashes of 1929 , 1987 and the boom of the Information Technology Era. Greenwood and Jovanovic (1999) and Hobijn and Jovanovic (2000) present a model of technological change that can replicate booms and crashes observed in financial data and can explain stock market valuations during the last 25 years. The main suggestion of the model is that new technologies destroy old, incumbent firms once the success of the new technology is made known to the market. Since new technologies are rarely formed by listed companies, and because listed companies usually resist their implementation, stock market valuations are depressed once new technologies are invented. This is because once small innovative firms are listed on the market, investors shift their attention to such companies and neglect 'old' technology firms that have lower growth potential.
} 


\section{REFERENCES}

Billio, M., Pelizzon, L., (2000): "Value at Risk: A Multivariate Regime Switching Approach”, Journal of Empirical Finance, Vol. 7, 531-554.

Blanchard O. J., (1979): "Speculative Bubbles, Crashes and Rational Expectations”, Economics Letters, Vol. 3, pp. 387-389

Blanchard O. J., Fischer S., (1989): "Lectures on Macroeconomics", (1st edition), Cambridge: MIT Press.

Blanchard O. J., Watson, M. W. (1982): "Bubbles, Rational Expectations and Financial Markets", NBER Working Paper Series, No 945, pp. 1-30

Bohl M.T., (2000): "Periodically Collapsing Bubbles in the US Stock Market", Working Paper, Department of Economics, European University Viadrina Frankfurt (Oder)

Brooks, C., Katsaris, A. (2002) Forecasting the Collapse of Speculative Bubbles: An Empirical Investigation of the S\&P 500 Composite Index" ISMA Centre Discussion Paper No. 2002-04.

Campbell J., Shiller R., (1987): “Cointegration and Tests of Present Value Models”, Journal of Political Economy, 95, pp. 1062-1088

Chen J., Hong H., Stein J.C., (2001): "Forecasting Crashes: Trading Volume, Past Returns and Conditional Skewness in Stock Prices", Journal of Financial Economics, Vol. 61, No. 3, pp. 345-381

Cutler D. M., Poterba J. M. and Summers L. H., (1991): "Speculative Dynamics”, Review of Economic Studies, Vol. 58, pp. 529-546.

Diba B. T., Grossman H. I., (1988): “Explosive Rational Bubbles in Stock Prices?”, American Economic Review, Vol. 78, No 3, pp. 520-530

Evans G. W., (1991): "Pitfalls in Testing for Explosive Bubbles in Asset Prices", American Economic Review, Vol. 81, pp. $922-930$

Flood R. P., Garber P. (1980): "Market Fundamentals Versus Price Level Bubbles: The first Tests", Journal of Political Economy, 88, pp. 745-770

Flood R. P., Garber P., Scott L., (1984): "Multi Country Tests for Price Level Bubbles", Journal of Economic Dynamics and Control, Vol. 8, pp. 329-40

Greenwood J., Jovanovic B., (1999): "The Information-Technology Revolution and the Stock Market", American Economic Association Papers and Proceedings, Vol. 89, No. 2, pp. 116-122.

Hall S. G., Sola M., (1993): "Testing for Collapsing Bubbles; An Endogenous Switching ADF Test", discussion paper 15-93, London Business School

Hall S. G., Psaradakis Z., and Sola M., (1998): "Detecting Periodically Collapsing Bubbles: A Markov-Switching Unit Root Test", Journal of Applied Econometrics, Vol. 14, No. 2, pp. 143-154

Harvey C. R., Siddique A., (2000): “Conditional Skewness in Asset Pricing Tests”, Journal of Finance 55, No. 3, pp. 1263-1295

Harris M., Raviv A., (1993): "Differences of Opinion Make a Horse Race”, Review of Financial Studies, Vol. 6, No. 3, pp. 473-506

He H., Wang J., (1995): "Differential Information and Dynamic Behaviour of Stock Trading Volume", Review of Financial Studies, Vol.8, No. 4, pp. 919-972

Hobijn, B., Jovanovic B., (2000): "The Information-Technology Revolution and the Stock Market: Evidence", NBER Working Paper, No. 7684.

Hong H., Stein J. C., (1999): "Differences of Opinion, Rational Arbitrage and Market Crashes", NBER Working Paper.

Jorion, P. (2000): "Value at Risk: The New Benchmark for Controlling Market Risk", 2nd edition, Chicago: McGraw Hill.

Kandel E., Pearson N. D., (1995): "Differential Interpretation of Public Signals and Trade in Speculative Markets", Journal of Political Economy, Vol. 103, No. 4, pp. 831-72.

Karpoff J.M. (1986): “A Theory of Trading Volume”, Journal of Finance, Vol. 41, No. 5, pp. 1069-1087

Karpoff J.M. (1987): “The Relation Between Price Changes and Trading Volume: A Survey”, Journal of Financial and Quantitative Analysis, Vol. 22, No. 1, pp. 109-126.

Kindleberger C. P., (1989): "Manias, Panics and Crashes: A History of Financial Crises", Macmillan, London

Kraus A., Litzenberger R. H., (1976): "Skewness Preference and the Valuation of Risk Assets", The Journal of Finance, Vol. 31, No. 4, pp. 1085-1100.

Maheu, J. M., McCurdy T. H., (2000): "Identifying Bull and Bear Markets in Stock Returns", Journal of Business and Economic Statistics, Vol. 18, pp. 100-112.

Marsh A. T., Wagner N., (2000): "Return-Volume Dependence and Extremes in International Equity Markets", Working Paper, Haas School of Business, UC Berkley.

McQueen G., Thorley S., (1994): "Bubbles, Stock Returns, and Duration Dependence” Journal of Financial and Quantitative Analysis, Vol. 29, No 3, pp. 379-401.

Morgan I. G, (1976): “Stock Prices and Heteroscedasticity”, Journal of Business, Vol. 49, pp 496-508. 
Odean T., (1998): "Volume, Volatility, Price and Profit When All Traders Are Above Average", Journal of Finance, Vol. 53, No. 6, pp. 1887-1934.

Poterba, J. M., Summers L. H., (1988): "Mean Reversion in Stock Prices: Evidence and Implications", Journal of Financial Economics, Vol. 22, pp. 27-59.

Salge M., (1997): "Rational Bubbles: Theoretical Basis, Economic Relevance and Empirical Evidence with a Special Emphasis on the German Stock Market", Springer, Berlin

Scott, R., Horvath P., (1980): "On the Direction of Preference for Moments of Higher Order Than the Variance", Journal of Finance, Vol. 35, pp. 915-919

Shalen C.T. (1993): "Volume Volatility, and the Dispersion of Beliefs", Review of Financial Studies, Vol. 61, No. 2, pp. $405-434$

Shiller R. J., (1981): "Do Stock Prices move too much to be Justified by subsequent Changes in Dividends", American Economic Review, Vol.71, 421-36

Shiller R., (2000): "Irrational Exuberance", Princeton university Press, Princeton, New Jersey

Summers L. H., (1986): “Does the Stock Market Rationally Reflect Fundamental Values?”, The Journal of Finance, Vol. XLI, No 3, pp. 591-603

Tirole J., (1982): “On the possibility of Speculation Under Rational Expectations”, Econometrica, Vol. 50, No. 5, pp. 1163-1182.

van Norden S., (1996): "Regime Switching as a Test for Exchange Rate Bubbles", Journal of Applied Econometrics, Vol. 11 , No. 3 pp. 219-51.

van Norden S., Schaller H., (1993): "The Predictability of Stock Market Regime: Evidence from the Toronto Stock Exchange", The Review of Economics and Statistics, Vol. 75, No. 3, pp. 505-510

van Norden S., Schaller H., (1997): “Fads or Bubbles?”, Bank of Canada Working Paper 97-2: http://www.bankofcanada.ca/en/res/wp97-2.htm

van Norden S., Schaller H., (1999): "Speculative Behaviour, Regime-Switching, and Stock Market Crashes." in Nonlinear Time Series Analysis of Economic and Financial Data, Philip Rothman ed., pp. 321-356.

van Norden S., Vigfusson R., (1998): “Avoiding the Pitfalls: Can Regime Switching Tests Reliably Detect Bubbles?", Studies in Nonlinear Dynamics and Econometrics, Vol. 3, No. 1, pp. 1-22.

West K.D., (1987): “A specification Test for Speculative Bubbles”, Quarterly Journal of Economics, 102, pp. 553580.

West K. D., (1988): “Bubbles, Fads, and Stock Price Volatility Tests: A Partial Evaluation”, Journal of Finance, Vol. 43, pp. 639-660.

Ying C.C. (1966): “Stock Market Prices and Volumes of Sales”, Econometrica, Vol. 34, pp. 676-686.

Zeira J., (1999): "Informational Overshooting, Booms and Crashes", Journal of Monetary Economics, Vol. 43, No. 1, pp. 237-257. 


\section{TABLES AND FIGURES}

Table 1: Results of Periodically Collapsing Speculative Bubble Models.

January 1888 - January 2003.

$$
\begin{array}{ll}
r_{t+1}^{D}=\beta_{D, 0}+u_{t+1}^{D} & \operatorname{Pr}\left(W_{t+1}=D\right)=\Omega\left(\beta_{n, 0}+\beta_{n, B}\left|B_{t}\right|+\beta_{n, S} S_{t}^{f, a}\right) \\
r_{t+1}^{S}=\beta_{S, 0}+\beta_{S, B} B_{t}+\beta_{S, V} V_{t}^{x}+u_{t+1}^{S} & \operatorname{Pr}\left(W_{t+1}=S\right)=\left(1-\operatorname{Pr}\left(W_{t+1}=D\right)\right) \Omega\left(\beta_{q, 0}+\beta_{q, B}\left|B_{t}\right|+\beta_{q, V} V_{t}^{x}\right) \\
r_{t+1}^{C}=\beta_{C, 0}+\beta_{C, B} B_{t}+u_{t+1}^{C} & \operatorname{Pr}\left(W_{t+1}=C\right)=\left(1-\operatorname{Pr}\left(W_{t+1}=D\right)\right)\left(1-\operatorname{Pr}\left(W_{t+1}=S\right)\right)
\end{array}
$$

\begin{tabular}{|c|c|c|c|c|c|c|}
\hline \multirow[b]{2}{*}{ Coefficient } & \multicolumn{2}{|c|}{ Three-Regime Model } & \multicolumn{2}{|c|}{$\begin{array}{c}\text { Three-Regime Extension of } \\
\text { vNS (1999) Model }\end{array}$} & \multicolumn{2}{|c|}{$\begin{array}{l}\text { Original van Norden \& } \\
\text { Schaller (1999) Model }\end{array}$} \\
\hline & Value & $\begin{array}{l}\text { Standard } \\
\text { Error }\end{array}$ & Value & $\begin{array}{l}\text { Standard } \\
\text { Error }\end{array}$ & Value & $\begin{array}{l}\text { Standard } \\
\text { Error }\end{array}$ \\
\hline$\beta_{D, 0}$ & 1.0031 & 0.0002 & 1.0033 & 0.0003 & - & - \\
\hline$\beta_{S, 0}$ & 1.0118 & 0.0079 & 1.0118 & 0.0103 & 1.0084 & 0.0011 \\
\hline$\beta_{S, B}$ & 0.0385 & 0.0126 & 0.0528 & 0.0137 & 0.0004 & 0.0036 \\
\hline$\beta_{S, V}$ & 0.0732 & 0.0267 & - & - & - & - \\
\hline$\beta_{C, 0}$ & 0.9784 & 0.0228 & 0.9703 & 0.0269 & 0.9656 & 0.0154 \\
\hline$\beta_{C, B}$ & -0.1541 & 0.0355 & -0.1987 & 0.0370 & -0.0411 & 0.0198 \\
\hline$\beta_{n, 0}$ & 1.0183 & 0.1545 & 1.0881 & 0.2192 & - & - \\
\hline$\beta_{n, B}$ & -0.3806 & 0.1559 & -0.4858 & 0.2422 & - & - \\
\hline$\beta_{n, S}$ & -4.7454 & 1.8647 & - & - & - & - \\
\hline$\beta_{q, 0}$ & 2.8254 & 0.3846 & 1.3325 & 0.3991 & 1.8538 & 0.1729 \\
\hline$\beta_{q, B}$ & -2.0291 & 0.1023 & -0.5783 & 0.4446 & -1.3430 & 0.2959 \\
\hline$\beta_{q, V}$ & -6.1212 & 1.5169 & - & - & - & - \\
\hline$\sigma_{D}$ & 0.0295 & 0.0009 & 0.0297 & 0.0013 & - & - \\
\hline$\sigma_{S}$ & 0.0479 & 0.0045 & 0.0507 & 0.0050 & 0.0324 & 0.0010 \\
\hline$\sigma_{C}$ & 0.1091 & 0.0135 & 0.0901 & 0.0186 & 0.1046 & 0.0112 \\
\hline Restriction $\mathrm{H}_{1}$ & Statistic & $p$-value & Statistic & $p$-value & Statistic & $p$-value \\
\hline$\beta_{C, B}<0$ & 5.4093 & 0.0200 & 10.1226 & 0.0015 & 5.1197 & 0.0237 \\
\hline$\beta_{S, B}>\beta_{C, B}$ & 5.5019 & 0.0190 & 9.1709 & 0.0025 & 4.8548 & 0.0276 \\
\hline$\beta_{S, V}>0$ & 2.9460 & 0.0861 & - & - & - & - \\
\hline$\beta_{q, B}<0$ & 4.7575 & 0.0292 & 1.9271 & 0.1651 & 27.4445 & 0.0000 \\
\hline$\beta_{q, V}<0$ & 10.1961 & 0.0014 & - & - & - & - \\
\hline$\beta_{n, B}<0$ & 7.0836 & 0.0078 & 11.9127 & 0.0006 & - & - \\
\hline$\beta_{n, S}<0$ & 5.7630 & 0.0164 & - & - & - & - \\
\hline Model & Statistic & $p$-value & Statistic & $p$-value & Statistic & $p$-value \\
\hline Volatility Regimes & 83.0904 & 0.0000 & 65.5559 & 0.0000 & 52.3807 & 0.0000 \\
\hline Mixture of Normals & 57.1978 & 0.0000 & 39.6633 & 0.0000 & 49.9112 & 0.0000 \\
\hline 3 Regime vNS & 17.5345 & 0.0005 & - & - & - & - \\
\hline
\end{tabular}

The three-regime extension of the vNS (van Norden and Schaller) model is the same as the three-regime model but is estimated without the abnormal volume and the spread variables. The original van Norden and Schaller model results are the results of the methodology described in their paper (van Norden and Schaller (1999)) using our data and sample period. The volatility regimes test imposes the restrictions described in equations (14.1), (14.2) and (14.3). The mixture of normals imposes restriction (15) while the 3-regime vNS model imposes restriction (16). For the original vNS model the restrictions are the 2-regime equivalents of (14.1), (14.2), (14.3) and (26). Standard errors are calculated from the inverse of the Hessian at the optimum. 
Table 2: Speculative Bubble Models' Trading Rules Results against Randomly Generated Trading Rules and the Buy and Hold Strategy.

January 1946 - January 2003

\begin{tabular}{|c|c|c|c|c|c|c|c|c|c|c|}
\hline Strategy & $\begin{array}{l}\text { Mean } \\
\text { Return }\end{array}$ & $\begin{array}{l}\text { Standard } \\
\text { Deviation }\end{array}$ & Skewness & $\begin{array}{l}\text { Excess } \\
\text { Kurtosis }\end{array}$ & $\begin{array}{l}\text { End of } \\
\text { Period } \\
\text { Wealth }\end{array}$ & $\begin{array}{c}\text { Sharpe } \\
\text { Ratio }\end{array}$ & $\begin{array}{c}\text { \% of Time } \\
\text { in the } \\
\text { Market }\end{array}$ & $\begin{array}{c}\text { Number of } \\
\text { (round trip) } \\
\text { Trades }\end{array}$ & $\begin{array}{c}\text { Adjusted } \\
\text { Sharpe } \\
\text { Ratio }\end{array}$ & $\begin{array}{l}\text { Adjusted End of } \\
\text { Period Wealth }\end{array}$ \\
\hline Buy and Hold & $0.60 \%$ & $3.56 \%$ & -0.58 & 1.68 & $\$ 39.81$ & 0.1550 & $100.00 \%$ & 0 & 0.1532 & $\$ 39.81$ \\
\hline $\begin{array}{c}\text { Risk Free } \\
\text { Investment }\end{array}$ & $0.05 \%$ & $0.44 \%$ & -3.98 & 39.62 & $\$ 1.42$ & - & $0.00 \%$ & 0 & - & - \\
\hline $\begin{array}{c}3 \text { Regime } \\
\text { Model } \\
\text { Original vNS } \\
\text { Model }\end{array}$ & $\begin{array}{c}0.66 \% \\
(0.21 \%) \\
0.39 \% \\
(60.52 \%) \\
\end{array}$ & $\begin{array}{c}2.41 \% \\
(1.89 \%) \\
2.10 \% \\
(51.15 \%)\end{array}$ & $\begin{array}{c}0.45 \\
(0.15 \%) \\
-0.45 \\
(75.55 \%)\end{array}$ & $\begin{array}{c}2.88 \\
(0.01 \%) \\
10.99 \\
(0.03 \%)\end{array}$ & $\begin{array}{c}\$ 53.80 \\
(0.05 \%) \\
\$ 12.14 \\
(65.13 \%)\end{array}$ & $\begin{array}{c}0.2506 \\
(0.02 \%) \\
0.1601 \\
(55.56 \%)\end{array}$ & $\begin{array}{c}58.10 \% \\
- \\
33.87 \% \\
- \\
\end{array}$ & $\begin{array}{c}47 \\
- \\
19 \\
-\end{array}$ & $\begin{array}{c}0.2337 \\
- \\
0.1486 \\
- \\
\end{array}$ & $\begin{array}{c}\$ 47.70 \\
- \\
\$ 11.55 \\
- \\
\end{array}$ \\
\hline
\end{tabular}

Trading rules are formed based on the conditional probability of a crash when a positive bubble is present and the conditional probability of a rally when a negative bubble is present. The

investor either places his entire wealth in the S\&P 500 Composite Index or in the 3-month U.S. Treasury Bill. The end of period wealth is the real value of the investor's portfolio in January

2003 if the initial value of the portfolio in January 1946 was $\$ 1.00$. All the numbers and the returns are in real terms. Figures in parentheses show the percentile ranking of the trading rule relative to 10,000 random trading rules with an equal percentage of time invested in the index. The mean return is the average monthly real total return and the standard deviation of returns is the standard deviation of total returns. The Sharpe ratio is the ratio of the mean excess return of a given trading rule over the corresponding standard deviation of returns. The percentage of time in the market is the percentage of months the trading rule produced a hold signal out of the 685 months in the sample. The adjusted end of period wealth shows the end of period wealth net of transaction costs. Transaction costs are assumed to be $0.5 \%$ per round trip on the total value of the trade. 
Figure 1: Bubble Deviations of Actual Prices from Campbell and Shiller Fundamental Values. January 1888 - January 2003.

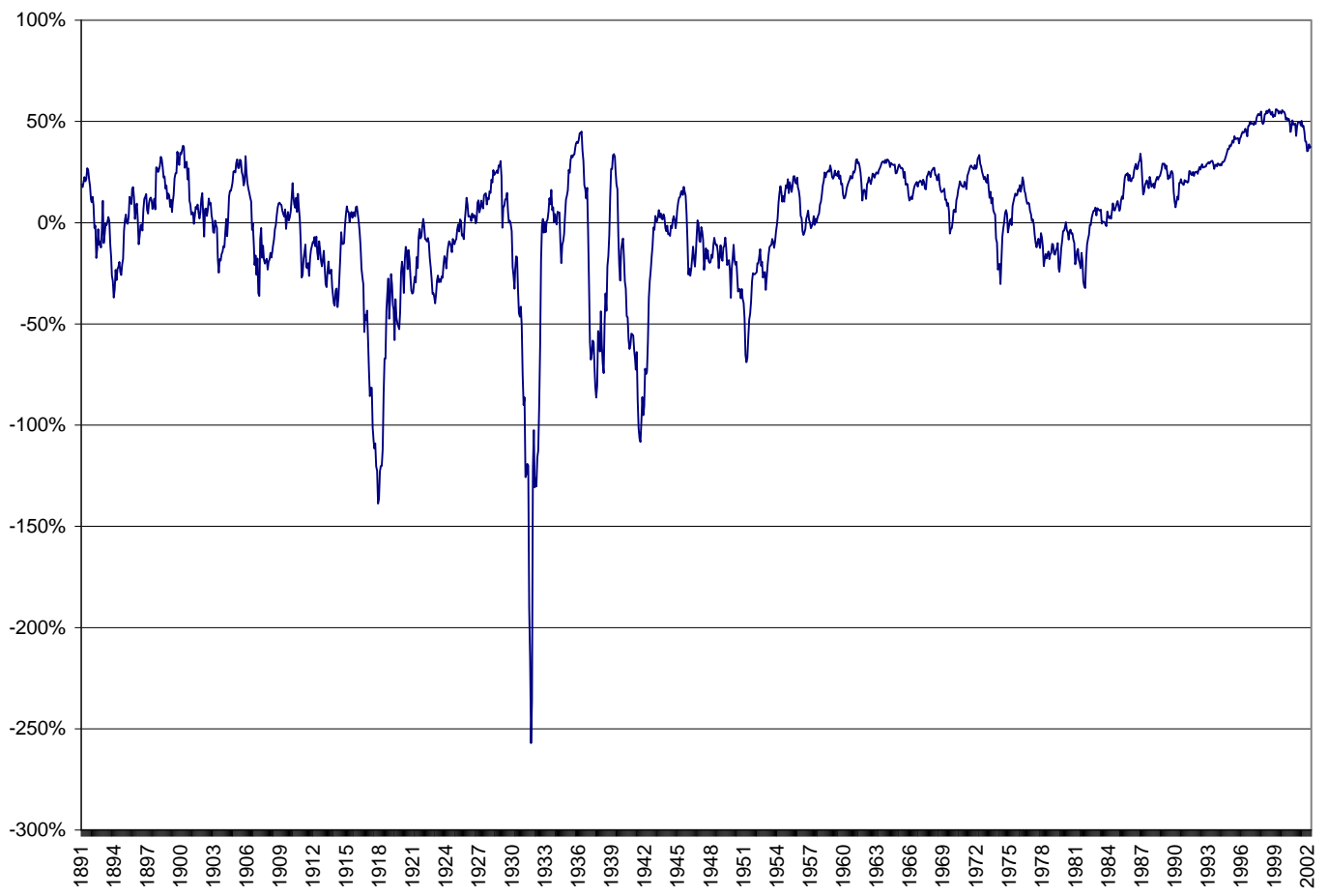

Figure 2: Probabilities of a Given Regime $(D, S$, or $C)$ in period $t+1$, Three-Regime Model. January 1888 - January 2003.

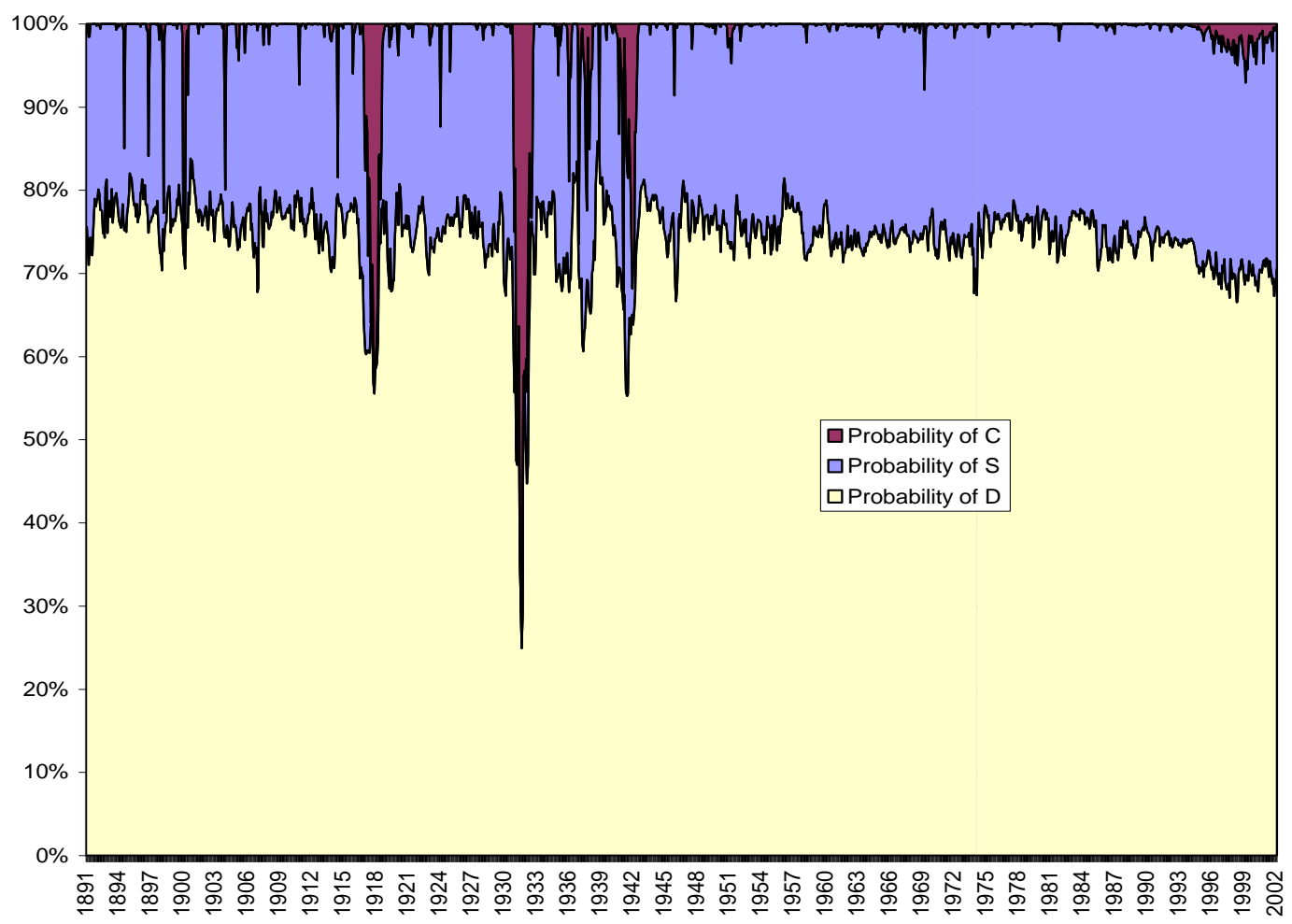


Figure 3: Probabilities of a Given Regime $(D, S$, or $C)$ in period $\mathrm{t}+1$, Extended van Norden and Schaller model. January 1888 - January 2003.

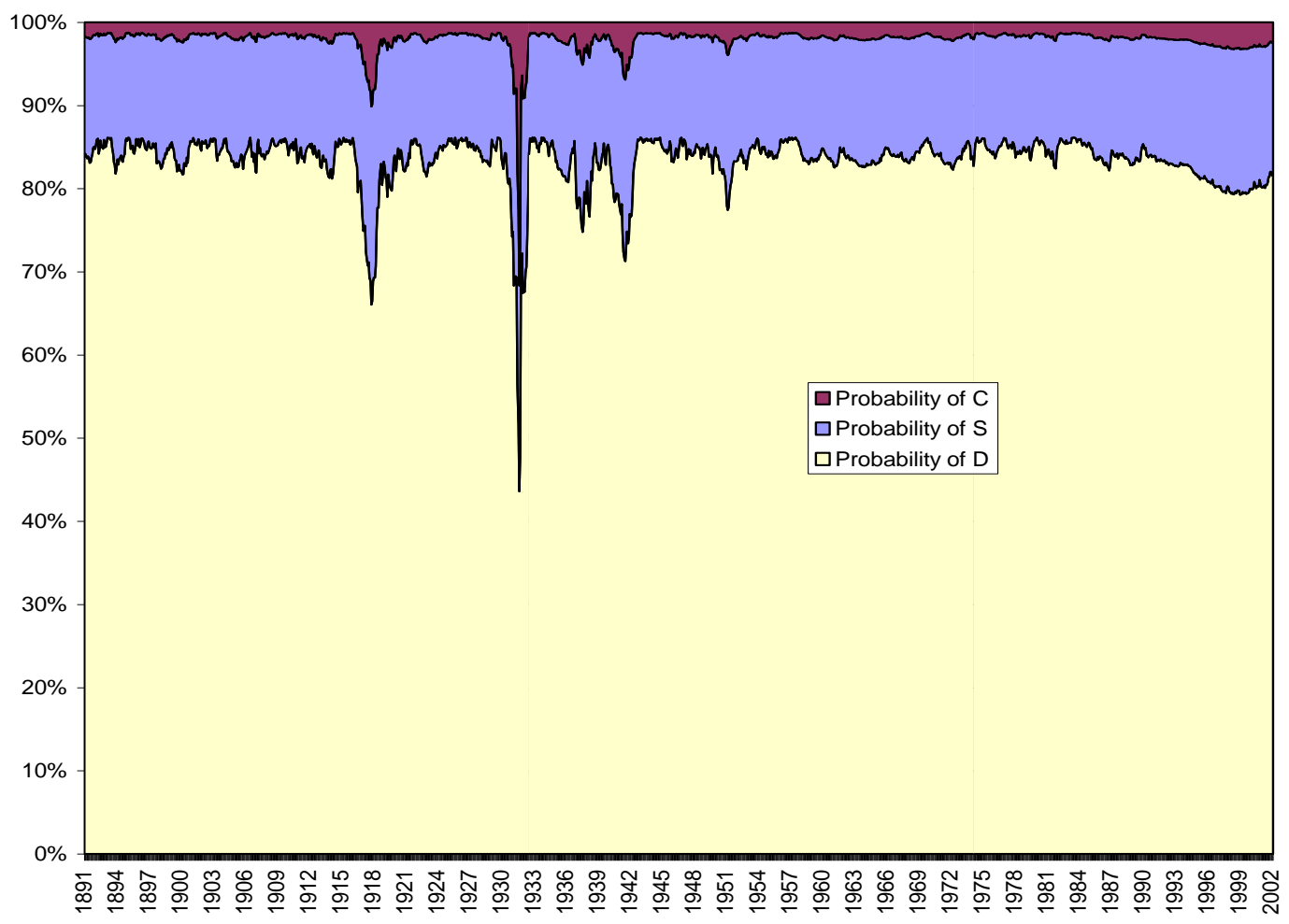

Figure 4: Probabilities of a Crash from the 3 Regime and the van Norden and Schaller Models. January 1946 - January 2003

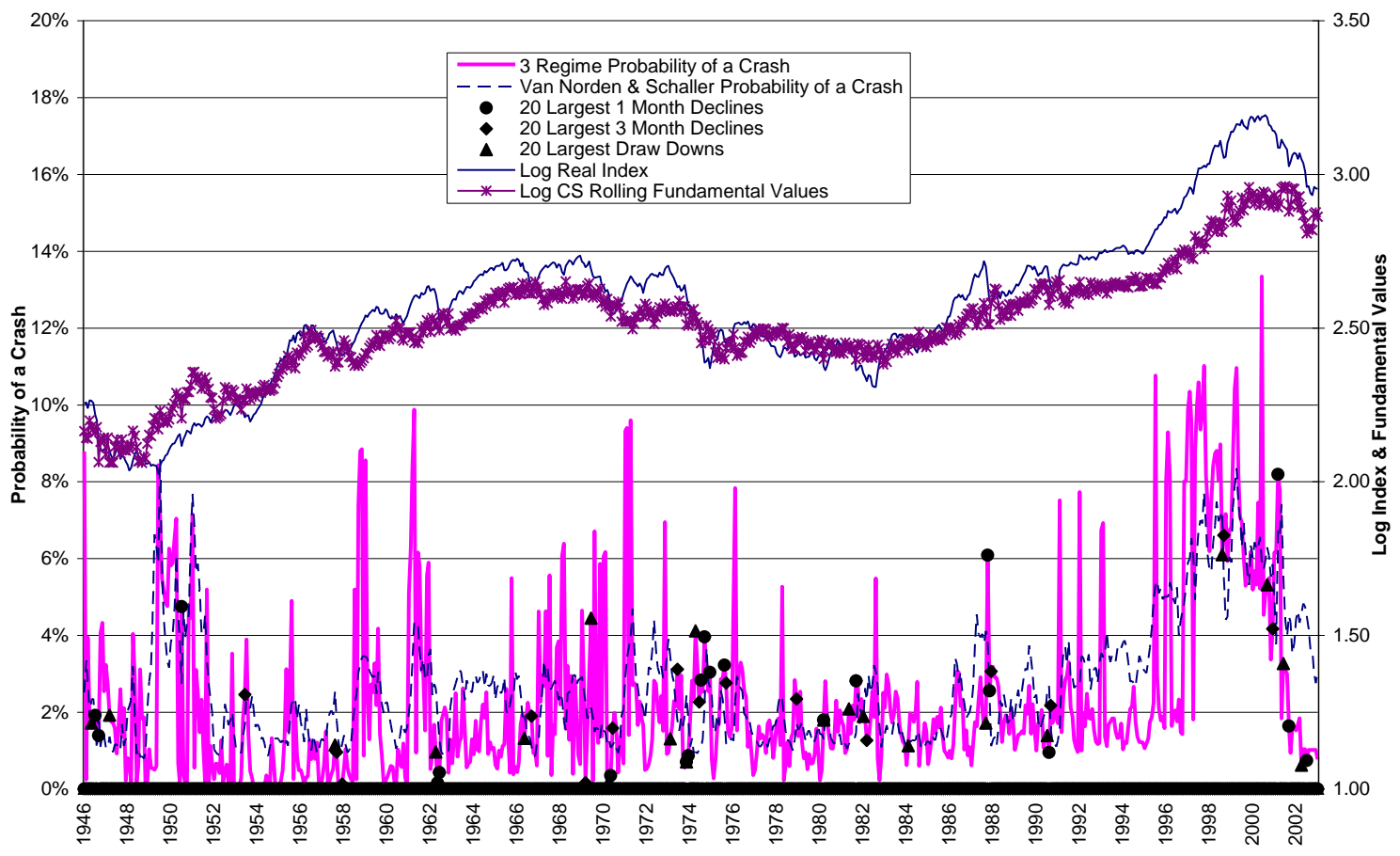


Figure 5: Probabilities of a Rally from the 3 Regime and the van Norden and Schaller Models. January 1946 - January 2003

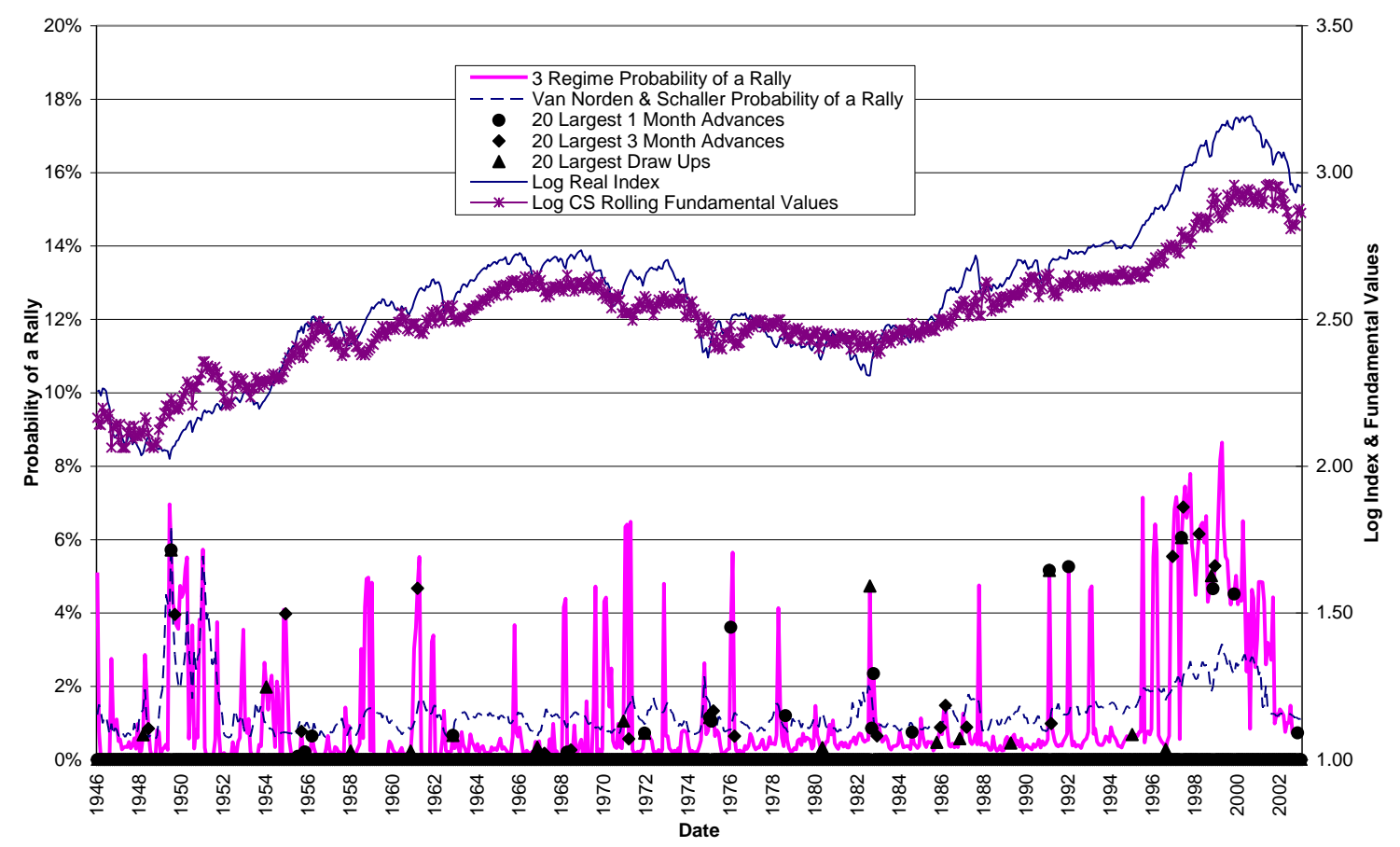

Figure 6: Net Excess Wealth (i.e. After the Deduction of Transaction Costs) Generated Using the 3 Regime Speculative Bubble Model Trading Rule, as a Percentage of the Buy and Hold Strategy Wealth. January 1946 - January 2003

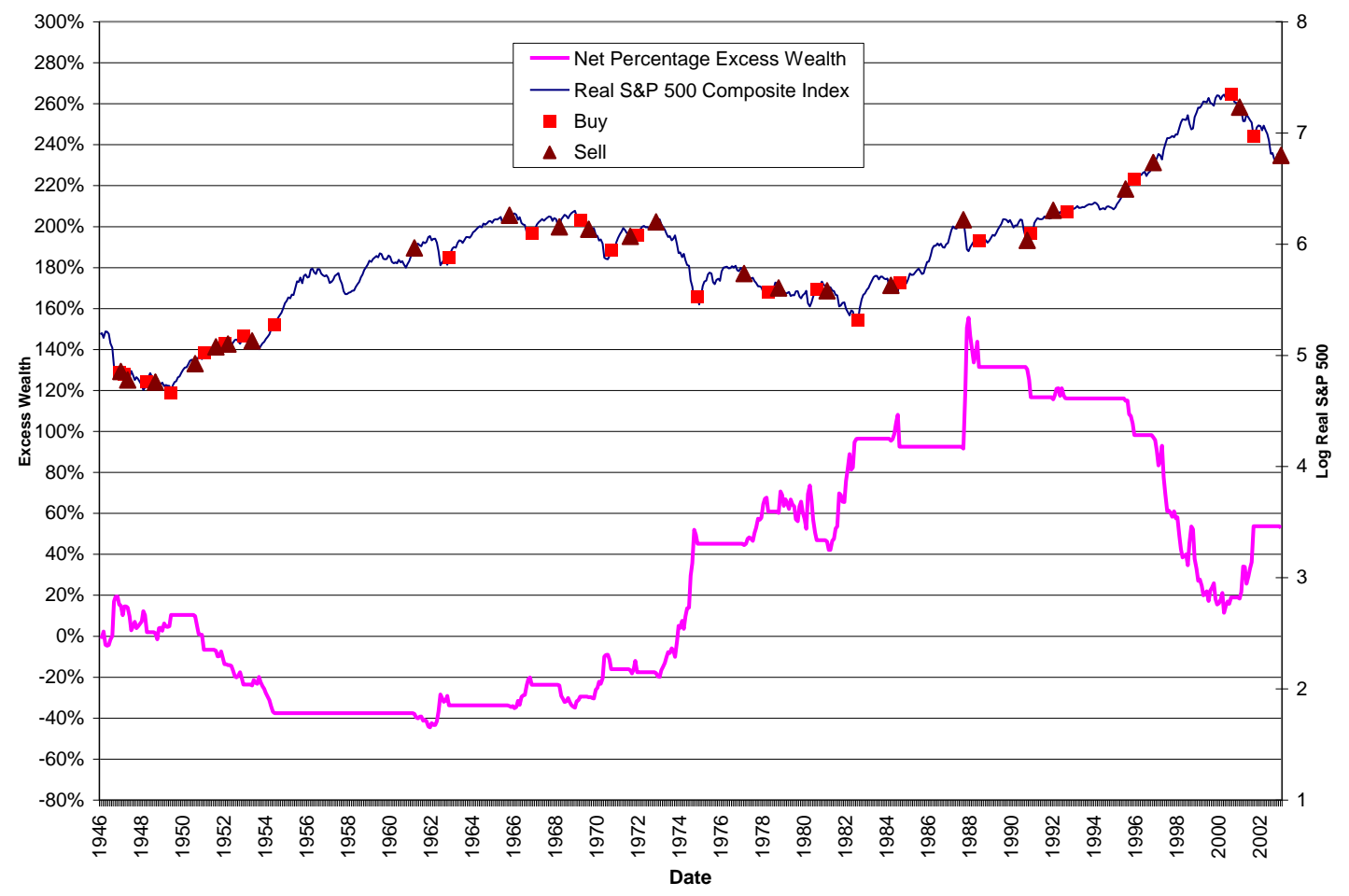

